\title{
Revisión de la secuencia cultural Orosí-Tempisque de la Gran Nicoya: Nuevos datos provenientes de las excavaciones del sitio Manzanillo (G-430 Mz)
}

\author{
Luis Sánchez
}

Arqueólogo independiente

sanchezdiaz2000@hotmail.com

\begin{abstract}
Resumen: Se presenta aquí una discusión sobre la periodización cultural a la luz de las excavaciones en el sitio Manzanillo entre 2007 y 2009. Se interpreta la estratificación cultural del yacimiento que comprende los periodos regionales Orosí y Tempisque. Se discuten estos puntos relevantes: 1- La fase Loma B como la ocupación inicial de la bahía Culebra; 2- la conexión entre los complejos Tronadora y Loma B, 3- la secuencia de los periodos Tempisque-Bagaces y 4- las transformaciones socioculturales y contactos con Mesoamérica.

Palabras clave: Costa Rica, arqueología, cronología, tipología cerámica, jade.

Reviewing Orosí-Tempisque cultural sequence of Greater Nicoya: New data from the excavations of the site Manzanillo (G-430Mz)

Abstract: Presented here is a discussion on cultural periodization in the light of the cultural perodization in the light of the excavations in Manzanillo site between 2007-2009 years. Cultural stratification reservoir comprising Orosí and Tempisque periods is interpreted. These highlights are discussed: 1- Loma B phase as the earliest occupation in Culebra Bay; 2- the connection between Tronadora and Loma B complexes, 3- the Tempisque-Bagaces periods sequence and 4-social and cultural transformations and contacts with Mesoamerica.
\end{abstract}

Keywords: Costa Rica, archaeology, chronology, ceramic typology, jade.

Cuadernos de Antropología

Enero-Junio 2015, 25(1), 67-97

DOI: $10.15517 /$ cat.v25i1.19767

Recibido: 12-07-2014 / Aceptado: 24-03-2015

Revista del Laboratorio de Etnología María Eugenia Bozzoli Vargas

Escuela de Antropología, Universidad de Costa Rica

http://revistas.ucr.ac.cr/index.php/antropologia

ISSN 2215-356X

c) (1) (-) Cuadernos de Antropología está bajo una licencia Creative Commons Attribution-NonCommercial-ShareAlike 3.0 


\section{Manzanillo en el contexto de las investigaciones arqueológicas en bahía Culebra}

Culebra es una bahía angosta de aproximadamente $14 \mathrm{Km}$ de largo por $8 \mathrm{Km}$ de ancho que está situada en el borde de la península de Nicoya en el noroeste de Costa Rica (10³5' N y 8540' W) (Figura 1). La topografía accidentada y rocosa que la circunda hace que en su litoral predominen acantilados, playones estrechos y orillas pedregosas, en las cuales se combinan ecosistemas de arrecifes, estuarios y manglares de gran potencial biótico. Arqueológicamente, se ha demostrado que estos recursos costeros fueron a plenitud, apreciados por los prehispánicos: zonas residenciales de considerable tamaño y con depósitos densos de restos faunísticos, localidades específicas de extracción de sal y dentro del paisaje cultural, varias trampas circulares para la pesca, formadas por muros de piedra de arquitectura precolombina.

Un inventario de sitios arqueológicos fue levantado a principios de los ochentas (Lange y Abel-Vidor, 1980), sin embargo, para entonces, ya se tenía conocimiento de un sitio de características monumentales, Papagayo, situado en la prominencia de la pequeña península homónima. En este sitio se edificó un centro ceremonial, principalmente ocupado en los periodos Bagaces y Sapoá, hacia 600-1300 d.C. (Baudez et al., 1992).

Antes de Manzanillo y después de Papagayo, los sitios mejor estudiados fueron Vidor y Nacascolo, los cuales no solo proveyeron información muy completa sobre patrones funerarios, sino también contribuyeron a establecer un marco cronológico de la historia cultural de la bahía, la que se prolongó desde 800 a.C. hasta los albores de la conquista (Gutiérrez, 1993, 1998; Hardy, 1992; Lange, 1980; Lange y Abel-Vidor, 1980; Lawrence, 1989; Vázquez, 1986).

El desarrollo turístico de esta área promovió una investigación arqueológica coordinada en diversos sectores de la bahía; por su tamaño, ubicación, temporalidad y características culturales, Manzanillo fue uno de los mayormente estudiados (Hernández, 1998; Herrera y Solís, 2008; Solís, 1998; Solís y Herrera 2005) y el de mayor potencial en cuanto a la parte más temprana de la secuencia de bahía Culebra. Se estima que este sitio cubrió unas siete hectáreas, ocupando dos amplias terrazas que se extienden casi desde la costa hasta cerca de la parte más alta de la península de Nacascolo. Se identificaron aquellas áreas relacionadas con la ocupación del Periodo (P.) Tempisque, muestreándose ampliamente depósitos domésticos repletos de restos culturales. Anteriormente, Hernández (1998), descubrió y excavó allí, parte de un conjunto funerario de la parte más tardía del periodo.

La importancia de Manzanillo para documentar las ocupaciones costeras tempranas en Bahía Culebra, llevó a que se diera continuidad a la investigación por medio de excavaciones expresamente dirigidas a estudiar los contextos domésticos con mayor detalle. De ese modo, el autor realizó un proyecto de investigación a partir de 2007, el cual fue financiado en su totalidad por la empresa Ecodesarrollo Papagayo S.A. 


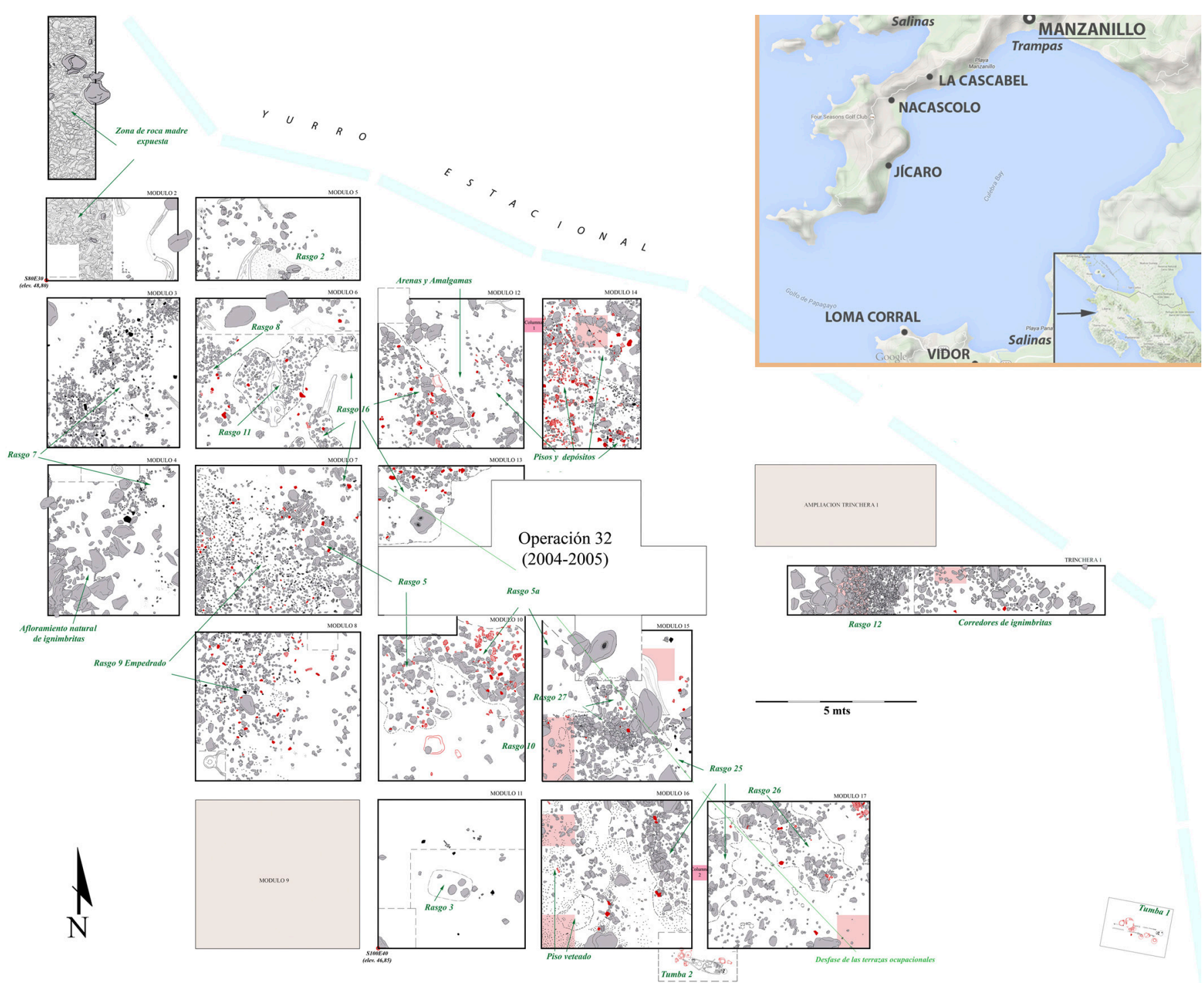

Figura 1: Localización del sitio Manzanillo (G-430Mz) y planta general de la excavación del Sector 2 (temporadas 2007-2009), mostrando los depósitos y rasgos relevantes de la secuencia ocupacional Orosí y Tempisque. Recuadros tomados de Google Earth.

\section{Las excavaciones en Manzanillo 2007-2009}

Las investigaciones se concentraron sobre tres sectores puntuales situados en la terraza más baja del sitio y de vista al mar. En los sectores 6 y 7, las operaciones cubrieron 23 y 30 metros cuadrados, respectivamente; mientras tanto, la excavación principal, la del Sector 2, se extendió por unos 400 metros. En esta 
última, se realizó un decapado horizontal dividido en diecisiete módulos de 5 x $5 \mathrm{~m}$ separados por muros de $50 \mathrm{~cm}$ de ancho como testigos estratigráficos (véase el plano en la figura 1). Debido a la dificultad de discernir estratos naturales, se ideó un sistema de muestreo vertical basado en micro-niveles de $5 \mathrm{~cm}$ de espesor y para obtener un control espacial más eficiente, se dispuso de un cuadriculado de unidades de 0,5 x 0,5 m. Para asegurar muestras nutridas de desechos culturales y bióticos, cerca de las dos terceras partes de todos los sedimentos excavados se colaron sobre cernidores de 1/8 de pulgada.

La evidencia suministrada por las excavaciones describe la utilización longeva de la terraza en distintos episodios, sin lugar a dudas, las ocupaciones Orosí y Tempisque fueron las más intensivas y duraderas (véase la periodización regional en la figura 2). No obstante, hay indicios de una supuesta ocupación del P. Arcaico a juzgar por un par de instrumentos lasqueados y un canto con desgaste que se hallaron bajo un metro de sedimentos estériles después de que se recuperaron los últimos niveles cerámicos. El sitio sería reutilizado de manera importante durante las fases Sapoá y Ometepe, donde se identificaron algunas sepulturas individuales y un rasgo intrusivo de grandes proporciones.

El decapado horizontal del Sector 2 descubrió pisos ocupacionales relacionados con la presencia permanente, o al menos frecuente, de grupos que convirtieron la terraza en un espacio de habitación y el escenario de diversas actividades domésticas. Los niveles ocupacionales se distinguen por la recurrencia de áreas empedradas sobre y alrededor de las cuales tuvieron lugar diversos procesos de trabajo. Algunas de estas se relacionan con el desprendimiento de rocas muy deterioradas del manto natural subyacente, pero una buena cantidad, son ignimbritas rodadas y angulares de mayor dureza deliberadamente apiladas formando corredores o pequeñas plataformas. Aunque estos rasgos han sido en otros casos relacionados con eventos funerarios, suponemos que su función aquí fue la de proveer espacios secos y firmes para sortear las irregularidades del terreno, contrarrestar la inestabilidad de los suelos arcillosos y húmedos y, a la vez, tener a mano materias primas potenciales para diversas faenas domésticas. En efecto, muchas de las piedras comúnmente asociados a estas concentraciones eran asientos, yunques, molejones, morteros o martillos. Varios de estos empedrados pudieron ser parte de áreas habitacionales; si bien no fueron ubicados con claridad pisos de viviendas, se observaron en cercanía a estos corredores, suelos compactados estratigráficamente colindantes.

Las excavaciones proveyeron voluminosas muestras de artefactos cerámicos y líticos así como una muestra abundante de fauna vertebrada. Por lo general, la preservación de las muestras cerámicas fue aceptable y permitió la caracterización de diferentes conjuntos morfológicos y estilísticos para los distintos episodios de ocupación y para algunos rasgos específicos. La amplia secuencia de ocupación y la forma como estratigráficamente se separaron los diferentes componentes estimularon el establecer una clasificación cerámica propia con categorías más específicas a las ya conocidas en la tipología vigente de los periodos Orosí y Tempisque de la Gran Nicoya (Sánchez, 2010). 


\begin{tabular}{|c|c|c|c|c|c|c|c|c|}
\hline \multicolumn{3}{|c|}{ PERIODO CULTURAL } & \multicolumn{6}{|c|}{ FASES LOCALES } \\
\hline Años & & Gran Nicoya & \multicolumn{2}{|c|}{ Bahía Culebra } & $\begin{array}{l}\text { Valle del } \\
\text { Tempisque }\end{array}$ & $\begin{array}{l}\text { Cordillera } \\
\text { de Tilarán }\end{array}$ & Istmo de Rivas & $\begin{array}{l}\text { Bahía de } \\
\text { Tamarindo }\end{array}$ \\
\hline 1550 & \multirow{10}{*}{$\begin{array}{l}5 \\
\frac{8}{0} \\
\frac{0}{0} \\
0\end{array}$} & \multirow{5}{*}{ OMETEPE } & \multirow{5}{*}{\multicolumn{2}{|c|}{ Ruiz }} & \multirow{5}{*}{ Bebedero B } & \multirow{5}{*}{ Tilarán } & \multirow{5}{*}{ Alta Gracia } & \multirow{5}{*}{ Bebedero B } \\
\hline 1450 & & & & & & & & \\
\hline 1400 & & & & & & & & \\
\hline 1350 & & & & & & & & \\
\hline 1300 & & & & & & & & \\
\hline 1250 & & \multirow{9}{*}{ SAPOÁ } & \multirow{3}{*}{\multicolumn{2}{|c|}{ Iguanita }} & \multirow{3}{*}{ Bebedero A } & \multirow{14}{*}{ El Silencio } & \multirow{3}{*}{ Las Lajas } & \multirow{3}{*}{ Bebedero A } \\
\hline 1200 & & & & & & & & \\
\hline 1150 & & & & & & & & \\
\hline 1100 & & & \multirow{4}{*}{\multicolumn{2}{|c|}{ Monte del Barco }} & \multirow{4}{*}{ Palo Blanco B } & & \multirow{4}{*}{ La Virgen } & \multirow{4}{*}{ Tamarindo B } \\
\hline 1050 & & & & & & & & \\
\hline 1000 & \multirow{11}{*}{$\begin{array}{l}> \\
0 \\
0 \\
0 \\
0 \\
0 \\
0\end{array}$} & & & & & & & \\
\hline 950 & & & & & & & & \\
\hline 900 & & & \multirow{4}{*}{\multicolumn{2}{|c|}{ Panamá }} & \multirow{4}{*}{ Palo Blanco A } & & \multirow{4}{*}{ Apompua } & \multirow{4}{*}{ Tamarindo A } \\
\hline 850 & & & & & & & & \\
\hline 800 & & & & & & & & \\
\hline 750 & & & & & & & & \\
\hline 700 & & & & & & & & \\
\hline 650 & & BAGACES & & & & & Dolo NTan & \\
\hline 600 & & & & & San Bosco & & Palos Negros & Matapalo \\
\hline 550 & & & & & & & & \\
\hline 500 & & & & & & & & \\
\hline 450 & & & & & & & & \\
\hline 400 & & & Mata de UVa & MATA DE UVA & Cimulas & & San Roque & I as Minas \\
\hline 350 & & & Mata de uva & II & Ciruelas & Arenal Tardío & & Las IMmnas \\
\hline 300 & & & & & & & & \\
\hline 200 & & TEMPISOUE & & MATA DE UVA & & & San Jorge & \\
\hline 100 & & IEMPISQUE & & $I$ & & & san Jorge & \\
\hline 0 & & & Orco & & Cataling & & & Montefresco \\
\hline 100 & 욤 & & Urso & $O R S O$ & Catalına & & Aviles & Montefresco \\
\hline 200 & $\stackrel{0}{=}$ & & & ORSO & & & & \\
\hline 300 & 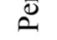 & & & & & $\begin{array}{l}\text { Arenal } \\
\text { Temnrano }\end{array}$ & & \\
\hline 400 & & & & & & & & \\
\hline 500 & & & & LOMA B II & & & & \\
\hline 600 & & OROSI & Loma B & & & & & \\
\hline 700 & & & & LOMA B I & & Tronadora & & \\
\hline 800 & & & & & & Tardío & & \\
\hline 1000 & & & & & & & & \\
\hline
\end{tabular}

Figura 2: Periodización Regional de la Gran Nicoya con la secuencia de fases Orosí Tardío-Tempisque propuesta (en sombreado). Adaptado de Vázquez et al, (1994).

Los artefactos líticos se separaron en diferentes industrias entre las que sobresalen, en orden de importancia, la de lasqueo, principalmente, de nódulos silíceos; la de picado en general (percutores, manos, machacadores, bases de molienda y yunques) y; la de abrasión. Destacan los siguiente rasgos en los conjuntos de 
instrumentos de piedra en Manzanillo: 1) predominio de materias primas del medio local como cantos y bloques de ignimbritas; 2) énfasis en procesos de manufactura más que en aquellos ligados a la preparación de alimentos, lo cual se refleja en el alto índice de instrumentos de percusión y abrasión; 3) procedimientos de lasqueo principalmente tendientes a la obtención de punzones, perforadores y buriles; 4) figuras, accesorios, adornos corporales sobre piedras ordinarias y semipreciosas en etapas iniciales o intermedias de manufactura y 5) reciclaje de instrumentos malogrados o inservibles, en general, la mayoría terminó reutilizándose como percutor o plataforma.

La metodología de decapado horizontal en micro-niveles posibilitó observar la extensión, espesor y densidad de diferentes depósitos, los más profundos sedimentaron sobre una depresión en dirección noroeste-sureste que parece corresponder a un lecho de una antigua quebrada. Sin embargo, estos depósitos del P. Tempisque (fase Mata de Uva) no son los más antiguos, ya que fuera de la zona de la depresión, se descubrieron niveles ocupacionales con componentes cerámicos muy distintos y con características más afines con el P. Orosí. Ambos pisos llegaron a separarse por medio de una discontinuidad del terreno a la altura del Módulo 15, la que parece coincidir con el borde del antiguo desagüe que secó o desvió, luego de que los habitantes de dicho periodo abandonaran el sitio. En este caso, los pisos más antiguos y menos densos en restos tienen menos profundidad (módulos 10, 15, 16 y 17), mientras que los más recientes, dentro del lecho, alcanzan hasta los 3 metros (módulos 12 y 14).

El discernimiento de la dinámica de ocupación del sitio, aunado a la clasificación de los componentes culturales, posibilitó establecer una secuencia para Manzanillo consistente en cincos fases locales (Sánchez, 2010) dentro del rango de ocupación Orosí y Tempisque. Se reafirman muchos aspectos sobre la cronología cultural en boga, pero se ponen en cuestionamiento criterios de periodización, contexto cultural y tipología cerámica. En los apartados que siguen, se puntualizan los temas relevantes. La discusión se organiza en el orden de la cronología regional. En primer lugar, se sintetizan los datos actuales sobre el periodo Orosí y a partir de allí, las implicaciones contextuales y evidencia concreta del componente cerámico más temprano de Manzanillo correspondiente a la fase conocida como Loma B. Se incluye aquí el cuestionamiento de si esta fase debe verse como parte de un proceso sociocultural circunscrito a Orosí o bien, como parte del Tempisque. En el siguiente punto, abordamos los criterios principales que marcan el desarrollo inicial del Periodo Tempisque en la Gran Nicoya para lo cual la evidencia de Manzanillo y de bahía Culebra pertinente a la fase Orso dan un gran aporte. Enseguida, se analiza la evidencia circunscrita al apogeo del P. Tempisque relacionada con cambios graduales en la organización y complejidad social. Un punto de discrepancia tiene que ver con aspectos de datación, tipología y contexto que definen el salto al P. Bagaces. 


\section{La fase Loma B y los antecedentes "formativos" en la Gran Nicoya}

El descubrimiento y fechamiento de diferentes complejos cerámicos bicromos anteriores al 500 a.C. (Corrales, 1989; Hoopes, 1987; Snarskis, 1978) en Costa Rica darían bases concretas para abordar la interrogante de cómo las poblaciones locales adoptan la tecnología alfarera, su impacto socioeconómico y cultural y de cómo se sucedería la transición hacia la sociedad agrícola aldeana. En este sentido, el término "formativo" (Willey y Phillips, 1958) ha dejado de ser el más acertado para describir la trayectoria cultural de los sistemas sociales en la Baja América Central. Aquí, en las zonas donde se brindan datos de la secuencia Arcaico-Orosí, la introducción de la alfarería, ya sea como invención independiente o re-invención, no constituyó en sí misma cambios sustanciales en el modus vivendi de la sociedad del momento como supone el concepto clásico del paralelismo entre vida sedentaria, la agricultura y la alfarería (Cooke, 1995; Hoopes, 1987, 1995). Para Hoopes (1995), la aparición de la cerámica en los bosques tropicales del sur de la América Central surge en el contexto de la interacción de cazadores-recolectores-horticultores en el que la producción cerámica fue solo una estrategia del uso intensivo de ciertos cultígenos por grupos humanos que aun mantenían gran movilidad.

Si bien peculiaridades distinguen a algunos de los complejos cerámicos más tempranos, no existe uno suficientemente distinto de los demás como para proponer para entonces divisiones culturales claras. Corrales (2000) apunta la separación en términos de un ordenamiento general entre grupos norteños y sureños, pero las afinidades formal-estilísticas se siguen sucediendo según ejes sur-norte entre las poblaciones alfareras tal y como lo indican las formulaciones de la lingüística histórica y genética a partir de grupos modernos (Barrantes et al., 1990; Constenla, 1991; Cooke y Ranere, 1992). Las correspondencias son tales entre estos complejos que puede sustentarse la idea de que el "horizonte bicromo inicial" en territorio costarricense constituyó un periodo de pocos cambios a nivel sociocultural y que la disgregación territorial por parte de grupos alfareros tomó su tiempo.

Para la Gran Nicoya, los focos de desarrollo del periodo prealdeano están documentados por diferentes complejos: Dinarte en Nicaragua Sur-oriental, la Pochota en la cuenca baja del Tempisque, Chaparrón en la Vertiente Atlántica Norte y, en especial, en la cordillera de Tilarán, donde ha sido mejor sustentado el contexto arqueológico para este periodo. Fechas ${ }^{14} \mathrm{C}$ cuidadosamente evaluadas provenientes del sitio Tronadora Vieja, donde se halló continuidad de ocupación Arcaico-Orosí, estiman en 2860 (1822)1000 a.C. la ocupación de la cuenca, que dejó evidencia de viviendas circulares asociadas a fogones, estructuras, pozos y otros rasgos y artefactos domésticos (todas las fechas y rangos en el texto incorporan calibración 
dendrocronológica, véase el cuadro 1). El entorno de una antigua laguna que ofrecía determinados recursos acuáticos y silvestres favoreció, según Hoopes (1987), la permanencia de grupos desde épocas precerámicas en la cuenca del Arenal.

La vajilla Tronadora, hasta la fecha principalmente documentada en contextos domésticos, es de apreciable homogeneidad tecnológica y estilística, lo cual se refleja en la persistente calidad de sus pastas, el recurrente patrón decorativo de incisos anchos precocción y el predominio de la denominada "olla-tecomate", la que, sin embargo, se sigue tratando esencialmente de una vasija que no es de abertura restringida. Los recipientes de abertura más amplia y bases menos profundas, entendemos, funcionan mejor para la cochura lenta o bien, de forma indirecta a partir de la sumersión de piedras calientes, lo cual se recalca en las evidencias de la cuenca del Arenal para el Arcaico y Orosí (Hoopes, 1987; Sheets, 1994).

La longevidad de la cerámica Tronadora aunada a la comprimida estratificación cultural de los sitios de la cuenca de Arenal ha dificultado identificar los cambios que prosiguen al P. Orosí Temprano. Hoopes (1987) reconoce un hiato significativo entre el 1000 y 400 a.C. que prácticamente lo imposibilita a estudiar el desenlace de la sociedad Orosí en las tierras altas. En los sitios del litoral del Pacífico Norte, por el contrario, no se identifican hasta la fecha componentes análogos a Tronadora, Chaparrón, Dinarte y La Pochota, lo que a falta de estudios más profundos, se estaría especulando en la relativamente tardía ocupación de hábitats costeros. Al respecto, la evidencia en el piso inferior de ocupación del sitio Vidor, bahía Culebra, merece ser destacada, pues se obtuvo la fecha de 1291 (988) 830 a.C. (Cuadro 1) relacionada con la fase Loma B; hasta hoy, el componente cultural radiométricamente fechado más temprano que se conoce en el litoral.

Loma B, en efecto, fue fechada por Lange (1980) con base en una muestra de carbón de los niveles basales del sitio Vidor en el que sobresale la presencia de los tipos Toya Tricromo (Figura 3A e I) y Palmar Ware entre otros y cuyo rasgo general es la decoración basada en incisos pre-cocción. Estas muestras proceden tanto del Montículo B (al parecer, unas pruebas estratigráficas realizadas por Holley Lange [1976; citado en Lange, 1980]) y de la excavación realizada este mismo año por Suzanne Abel-Vidor, unos $50 \mathrm{~m}$ al norte del anterior y no asociada a la secuencia de los montículos. Las muestras fechadas se obtuvieron de un pequeño hoyo adjunto a una hornilla (Abel-Vidor, 1980).

Los criterios estilísticos utilizados en ese entonces por Lange (1980) para Loma B son también razonables para argumentar un episodio precedente a las fases anteriormente establecidas para el llamado "Bicromo en Zonas" (P. Tempisque). En su momento, Coe y Baudez (1961) no advirtieron que la ausencia de Toya en la secuencia del "Bicromo" en playa Tamarindo podría indicar una fase ausente, que sí está presente bajo los concheros del sitio Chahuite Escondido, de la vecina península de Santa Elena. Otros tipos presentes en las muestras basales de Vidor asociadas a la misma fecha comprenden bordes y cuerpos de ollas similares al tipo Palmar, antaño, identificado y descrito por Bransford (1881) en la zona de Rivas, en Nicaragua, y posteriormente por Lothrop (1926). Palmar se caracteriza por bandas verticales de pintura roja o morada 
Cuadro 1: Fechas de Carbono 14 relacionadas a los periodos Orosí y Tempisque de la Gran Nicoya (Adaptado de: Hoopes [1987]; Vázquez et al. [1994]).

\begin{tabular}{|c|c|c|c|c|c|c|}
\hline $\begin{array}{l}\text { Código de } \\
\text { laboratorio }\end{array}$ & Fecha calibrada & $\begin{array}{c}2 \sigma \text { (intercepto } \\
\text { principal) }\end{array}$ & Sitio & Contexto & Referencia & Periodo/Fase \\
\hline Y-809 & $1530 \pm 280 \mathrm{AP}$ & $163(539)$ & \multirow[b]{2}{*}{ Matapalo } & Cut1:150-165 cm & \multirow[b]{2}{*}{ Coe y Baudez, 1961} & Te m p i s que / \\
\hline Y-810 & $\begin{array}{c}1870 \pm 200 \text { AP } \\
80 \pm 200 \text { d.C. }\end{array}$ & $\begin{array}{c}390 \text { a.C. } \\
\text { (129 d.C.) } 598\end{array}$ & & Cut2:135-150 cm & & $\begin{array}{c}\text { Te m p i s q u e / } \\
\text { Monte Fresco }\end{array}$ \\
\hline Y-1122 & $\begin{array}{c}1380 \pm 70 \mathrm{AP} \\
570 \pm 70 \text { d.C. }\end{array}$ & $\begin{array}{l}540(648) \\
796 \text { d.C. }\end{array}$ & \multirow{2}{*}{ Ayala } & Cut2:195cm & \multirow{2}{*}{ Norweb, 1964} & $\begin{array}{l}\text { Bagaces/ } \\
\text { Sta Isabel }\end{array}$ \\
\hline Y-1124 & $\begin{array}{l}1390 \pm 100 \mathrm{AP} \\
560 \pm 100 \text { d.C. }\end{array}$ & $\begin{array}{l}430(644) \\
866 \text { d.C. }\end{array}$ & & Cut2:285 cm & & $\begin{array}{l}\text { Tempisque/ } \\
\text { San Jorge }\end{array}$ \\
\hline GsY-100 & $\begin{array}{c}2195 \pm 130 \text { AP } \\
245 \pm 130 \text { d.C. }\end{array}$ & $\begin{array}{l}754 \text { (271 a.C. }) \\
60 \text { d.C. }\end{array}$ & \multirow{2}{*}{ Ortega } & Unidad L-nivel 6 & \multirow{2}{*}{ Baudez, 1967} & $\begin{array}{l}\text { Tempisque/ } \\
\text { Catalina }\end{array}$ \\
\hline Y-850 & $\begin{array}{c}1700 \pm 70 \text { AP } \\
250 \pm 70 \text { d.C. }\end{array}$ & $\begin{array}{l}132(325) \\
533 \text { d.C. }\end{array}$ & & Unidad L-nivel 6 & & $\begin{array}{l}\text { Tempisque/ } \\
\text { Catalina }\end{array}$ \\
\hline UCLA-2177A & $\begin{array}{c}2830 \pm 80 \text { AP } \\
880 \pm 80 \text { a.C. }\end{array}$ & $\begin{array}{l}1291(988) \\
830 \text { a.C. }\end{array}$ & \multirow{2}{*}{ Vidor } & $\begin{array}{c}\text { Feature } \\
\text { R.C.22 }\end{array}$ & \multirow{2}{*}{ Lange, 1980} & Orosí/ Loma B I \\
\hline UCLA-2177B & $\begin{array}{c}2200 \pm 60 \text { AP } \\
250 \pm 60 \text { a.C. }\end{array}$ & $\begin{array}{c}400(262) \\
90 \text { a.C. }\end{array}$ & & R.C.30 & & $\begin{array}{c}\text { Te m p i s que } / \\
\text { Orso }\end{array}$ \\
\hline ISGS-1132 & $\begin{array}{c}1650 \pm 100 \text { AP } \\
300 \pm 100 \text { d.C. }\end{array}$ & $\begin{array}{l}130(408) \\
637 \text { d.C. }\end{array}$ & \multirow{2}{*}{ Ramírez } & Estrato inferior & \multirow{2}{*}{ Noor, 1986} & $\begin{array}{l}\text { Tempisque/ } \\
\text { Arenal Tardío }\end{array}$ \\
\hline ISGS-1086 & $\begin{array}{c}1820 \pm 120 \text { AP } \\
130 \pm 120 \text { d.C. }\end{array}$ & $\begin{array}{l}93 \text { a.C. }(195 \\
\text { d.C.) } 529\end{array}$ & & Estrato inferior & & $\begin{array}{c}\text { Te m p i s que } / \\
\text { Arenal Medio }\end{array}$ \\
\hline UCLA-2167E & $\begin{array}{c}2110 \pm 80 \text { AP } \\
160 \pm 80 \text { a.C. }\end{array}$ & $\begin{array}{l}390 \text { (144 a.C. }) \\
54 \text { d.C. }\end{array}$ & El Carmen & Mont.2-Cache 7 & Ryder, 1986a & $\begin{array}{c}\text { Te m p i s qu e / } \\
\text { Arenal Medio }\end{array}$ \\
\hline UCLA-2163 & $\begin{array}{c}2250 \pm 60 \text { AP } \\
300 \pm 60 \text { a.C. }\end{array}$ & $\begin{array}{l}410(329) \\
132 \text { a.C. }\end{array}$ & \multirow{2}{*}{ Méndez } & Mont.1-nivel 3 & \multirow{2}{*}{ Norr,1986 } & $\begin{array}{l}\text { Tempisque/ } \\
\text { Catalina }\end{array}$ \\
\hline UCLA-2167A & $\begin{array}{c}3500 \pm 60 \text { AP } \\
1550 \pm 60 \text { a.C. }\end{array}$ & $\begin{array}{c}2028 \quad(1825) \\
1645 \text { a.C. }\end{array}$ & & Mont.1-nivel 4 & & Orosí/Naranjo \\
\hline Tx-5082 & $\begin{array}{l}1530 \pm 130 \text { AP } \\
420 \pm 130 \text { d.C. }\end{array}$ & $\begin{array}{l}230(539) \\
768 \text { d.C. }\end{array}$ & Viboriana & $\mathrm{B} 1 / \mathrm{B} 6$ & \multirow{5}{*}{ Hoopes, 1987} & $\begin{array}{l}\text { Tempisque/ } \\
\text { Arenal Tardío }\end{array}$ \\
\hline Tx-5270 & $\begin{array}{c}1410 \pm 80 \mathrm{AP} \\
540 \pm 80 \text { d.C }\end{array}$ & $\begin{array}{l}432(642) \\
770 \text { d.C. }\end{array}$ & \multirow{4}{*}{ Bolívar } & E18 & & $\begin{array}{l}\text { Tempisque/ } \\
\text { Arenal Tardío }\end{array}$ \\
\hline Tx-5271 & $\begin{array}{c}2340 \pm 170 \text { AP } \\
390 \pm 170 \text { a.C. }\end{array}$ & $\begin{array}{c}830 \text { (400 a.C. }) \\
1 \text { d.C. }\end{array}$ & & B17 & & $\begin{array}{l}\text { Orosí/Tronado- } \\
\text { ra Tardío (¿?) }\end{array}$ \\
\hline Tx-5272 & $\begin{array}{c}1770 \pm 60 \text { AP } \\
180 \pm 60 \text { d.C. }\end{array}$ & $\begin{array}{l}79(245) \\
410 \text { d.C. }\end{array}$ & & A8 & & $\begin{array}{l}\text { Tempisque/ } \\
\text { Arenal Tardío }\end{array}$ \\
\hline Tx-5273 & $\begin{array}{c}1660 \pm 70 \mathrm{AP} / \\
290 \pm 70 \text { d.C. }\end{array}$ & $\begin{array}{l}182 \text { (394) } 540 \\
\text { d.C. }\end{array}$ & & B6 & & $\begin{array}{c}\text { Tempisque/Are- } \\
\text { nal Tardío }\end{array}$ \\
\hline
\end{tabular}


Cuadro 1 (continuación): Fechas de Carbono 14 relacionadas a los periodos Orosí y Tempisque de la Gran Nicoya (Adaptado de: Hoopes [1986]; Vázquez et al. [1994]).

\begin{tabular}{|c|c|c|c|c|c|c|}
\hline $\begin{array}{l}\text { Código de } \\
\text { laboratorio }\end{array}$ & Fecha calibrada & $\begin{array}{c}2 \sigma \text { (intercepto } \\
\text { principal) }\end{array}$ & Sitio & Contexto & Referencia & Periodo/Fase \\
\hline Tx-5277 & $\begin{array}{l}3730 \pm 100 \mathrm{AP} / \\
1780 \pm 100 \text { a.C. }\end{array}$ & $\begin{array}{c}2470 \quad(2166) \\
1834 \text { a.C. }\end{array}$ & \multirow{2}{*}{ Tronadora } & V9 & \multirow{2}{*}{ Hoopes, 1987} & $\begin{array}{l}\text { Orosí/Tronado- } \\
\text { ra Temprano }\end{array}$ \\
\hline Tx-5279 & $\begin{array}{l}3480 \pm 320 \mathrm{AP} / \\
1530 \pm 320 \text { a.C. }\end{array}$ & $\begin{array}{c}2860 \quad(1822) \\
1000 \text { a.C }\end{array}$ & & W18 & & $\begin{array}{l}\text { Orosí/Tronado- } \\
\text { ra Temprano }\end{array}$ \\
\hline I-10804 & $\begin{array}{c}1830 \pm 80 \mathrm{AP} / \\
120 \pm 80 \mathrm{~d} . \mathrm{C} .\end{array}$ & $\begin{array}{l}86 \quad(173 \text { a.C. }) \\
390 \text { d.C. }\end{array}$ & \multirow{2}{*}{ El Tajo } & 7S6W-CT8 & \multirow{2}{*}{ Aguilar, 1983} & $\begin{array}{c}\text { Tempisque/Are- } \\
\text { nal }\end{array}$ \\
\hline SI-3459 & $\begin{array}{c}2170 \pm 65 \mathrm{AP} / \\
220 \pm 65 \text { d.C. }\end{array}$ & $\begin{array}{ll}390 & (265) \\
& 45 \\
& \text { a.C. }\end{array}$ & & 2S13W-CT8 & & $\begin{array}{c}\text { Tempisque/Are- } \\
\text { nal }\end{array}$ \\
\hline Beta- 35853 & $\begin{array}{c}2450 \pm 70 \mathrm{AP} / \\
500 \pm 70 \text { a.C. }\end{array}$ & 800-390 a.C. & La Regla & Entierro 5 & $\begin{array}{c}\text { Guerrero et al., } \\
1992\end{array}$ & Tempisque \\
\hline Beta- 205584 & $\begin{aligned} 1830 & \pm 40 \mathrm{AP} / \\
120 & \pm 40 \mathrm{~d} . \mathrm{C} .\end{aligned}$ & 90-260 d.C. & \multirow{5}{*}{ Manzanillo } & $\begin{array}{c}\text { OP32; S88E40; } \\
\text { N.19 }\end{array}$ & \multirow{3}{*}{$\begin{array}{r}\text { Herrera y Solís, } \\
2008\end{array}$} & $\begin{array}{l}\text { Te mp i s que/ } \\
\text { Mata de Uva I }\end{array}$ \\
\hline Beta-205585 & $\begin{array}{c}1800 \pm 40 \mathrm{AP} / \\
150 \pm 40 \mathrm{~d} . \mathrm{C} .\end{array}$ & 120-340 d.C. & & $\begin{array}{c}\text { OP32; S90E46; } \\
\text { N.17-18 }\end{array}$ & & $\begin{array}{c}\text { Te m p i s que/ } \\
\text { Mata de Uva I }\end{array}$ \\
\hline Beta-201660 & $\begin{array}{c}1760 \pm 40 \mathrm{AP} / \\
190 \pm 40 \mathrm{~d} . \mathrm{C} .\end{array}$ & 150-390 d.C & & $\begin{array}{c}\text { OP } 32 ; \quad \text { S88E42; } \\
\text { N.9 }\end{array}$ & & Tempisque \\
\hline Beta- 201658 & $\begin{array}{c}1640 \pm 40 \mathrm{AP} / \\
310 \pm 40 \mathrm{~d} . \mathrm{C} .\end{array}$ & 340-530 d.C. & & $\begin{array}{l}\text { OP37;Hornilla1; } \\
\text { N.8 }\end{array}$ & \multirow{2}{*}{$\begin{array}{ll}\text { Solís y Herrera, } \\
2005\end{array}$} & Tempisque \\
\hline Beta- 201659 & $\begin{array}{c}1770 \pm 40 \mathrm{AP} / \\
180 \pm 40 \mathrm{~d} . \mathrm{C} .\end{array}$ & 140-380 d.C. & & $\begin{array}{l}\text { OP37; Hornilla 2; } \\
\text { N.8 }\end{array}$ & & Tempisque \\
\hline
\end{tabular}

(como en las muestras de Manzanillo, Figura 3C) sobre el exterior de cuello alisado y característicos arreglos de la forma de "unión jack" sobre el cuerpo globular. Lange (1980) también señala la afinidad de los tipos Bocana Inciso (Figura 3J) -según definición original de Baudez (1967)- con el componente Loma B y de Schettel; no obstante, la definición tipológica y cronológica de este último no es del todo clara, pues en el istmo de Rivas se le considera de una fase posterior (Healy, 1980).

Otros datos a nivel estilístico y estratigráfico respaldan a la fase Loma B. En la secuencia obtenida por Haberland (1992) en Ometepe (Lago de Nicaragua), las fases Dinarte (cf. Tronadora/Chaparrón) y Ángeles permanecieron separadas por un nivel de tefra volcánica endurecida, mostrándose una clara separación estratigráfica y estilística entre esos componentes. La muestra hallada en el fondo de dos sondeos de prueba en el sitio Los Ángeles, sin mezcla con tiestos de fases posteriores, incluye justamente Toya, Palmar y Bocana incisos. Tipos como Rosales Esgrafiado y Schettel no están presentes aquí, sino hasta en 


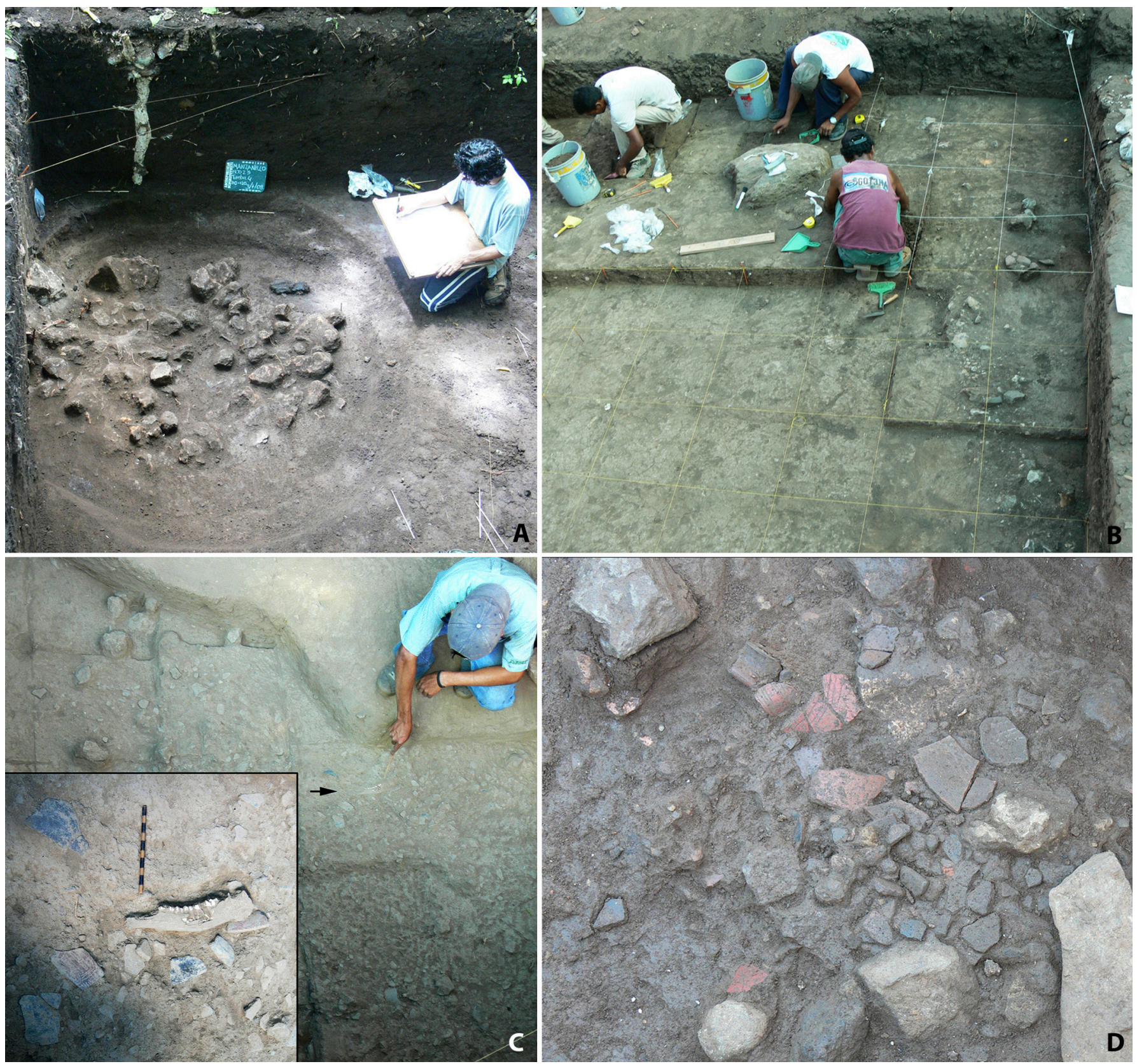

Figura 3: Excavaciones del sitio Manzanillo de las temporadas 2007-2009, sectores 2 (C-D) y 7 (A). A. Hornilla ritual rellena de ignimbritas y relacionada a un entierro primario flexionado, fase Loma B-II/Orso. B. Metodología de control espacial basada en cuadros de 0,5 x 0,5m. C y D. Piso final de ocupación de la fase Mata de Uva I mostrando desechos domésticos. 
las siguientes fases: Sinampa y Avilés en Rivas (Healy,1980). Reforzando esta escisión estratigráfica, vale la pena mencionar que en el sitio La Arenera, cerca de Managua, McCafferty y Salgado (2000) reportaron un componente que si bien asocia Usulután con Rosales y Schettel, se caracteriza por la ausencia de Bocana Inciso, que se sabe, aparece en sitios cerca de Managua. Un componente tipificado por las categorías principales de Loma B podría subyacer bajo gruesas capas de arena que conforman la estratificación de este sitio (McCafferty y Salgado, 2000).

\section{El componente Loma B en Manzanillo}

Del examen directo de las muestras de Loma B de Vidor por parte del autor, se determina que se trata del mismo componente cerámico presente en los niveles basales de Manzanillo (Figura 4). Los tipos antes descritos, Toya, Palmar, Diriá y Bocana a los que se les suman otros nuevos, representan entre el 93 y 97,6 $\%$ de los fragmentos diagnósticos en aquellos niveles $(80-140 \mathrm{~cm})$ de los módulos 15, 16, 22 y 23 . Solo están presentes en mínimas cantidades, elementos diagnósticos de la fase Orso, los cuales, sin excepción, nunca están en el nivel más profundo.

En general, la homogeneidad aquí es marcada; el precepto formal, al igual que en Tronadora, es el de una vajilla de abertura amplia con paredes interiores cuidadosamente tratadas. La vajilla Loma B se construyó con arcillas de buena calidad mezcladas con arenilla para asegurar sus capacidades térmicas y aislantes. En suma, los atributos de este conjunto lo hacen versátil y apropiado para uso culinario y al mismo tiempo como vajilla de servicio.

La muestra cerámica de Manzanillo permitió no solo detectar la fase Loma B a través de 3388 fragmentos de los contextos más confiables y reconstruir y ampliar la tipología con base en la ya existente, sino también proponer una subdivisión de la fase. Los grupos Toya, Palmar y Diriá junto a la vajilla monocroma lisa son más representativos de la primera parte de la fase (en los últimos $10 \mathrm{~cm}$ de depósitos, Toya y Palmar siempre suman más de $75 \%$ de la muestra). Los elementos Loma B II suelen aparecer más arriba en la estratificación (Figura 4J-R) diferenciándose en lo siguiente: 1) Los incisos anchos se extienden bajo zonas de engobe rojo; 2) se diversifican los diseños y sobresalen ciertos motivos zoomórficos; 3) aparece el diseño que denominamos "dentado", consistente en una línea en zig-zag y a veces trazada en espacios prominentes dentro o fuera de la vasija y, 4) se generaliza el estilo decorativo característico que alterna incisos múltiples y bandas rojas, esto es Bocana Inciso.

La distribución tipológica de los contextos de Manzanillo también pone en cuestionamiento el porqué, aún hoy, se sigue asumiendo que tipos como Toya, Palmar y Bocana persisten en el tiempo (Abel-Vidor et al., 1990; Baudez, 1967; Coe y Baudez, 1961), considerándolos representativos de toda la secuencia del P. Tempisque y no de una etapa previa o preliminar. Este hecho es comprensible en el caso de metodologías tradicionales de excavación basadas en niveles arbitrarios de $20 \mathrm{~cm}$ que impiden notar diferencias sutiles 

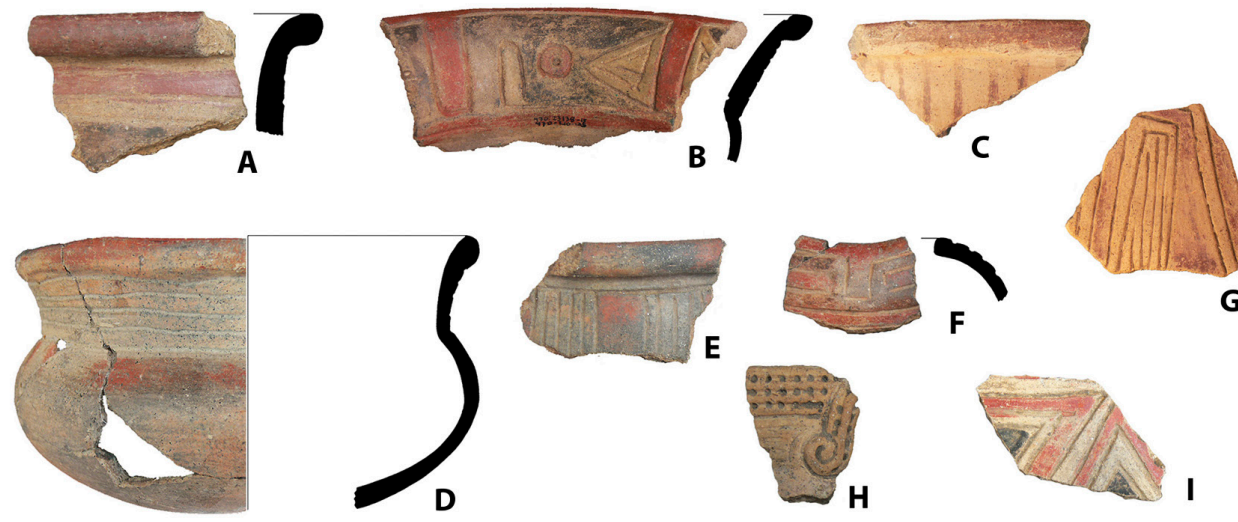

G
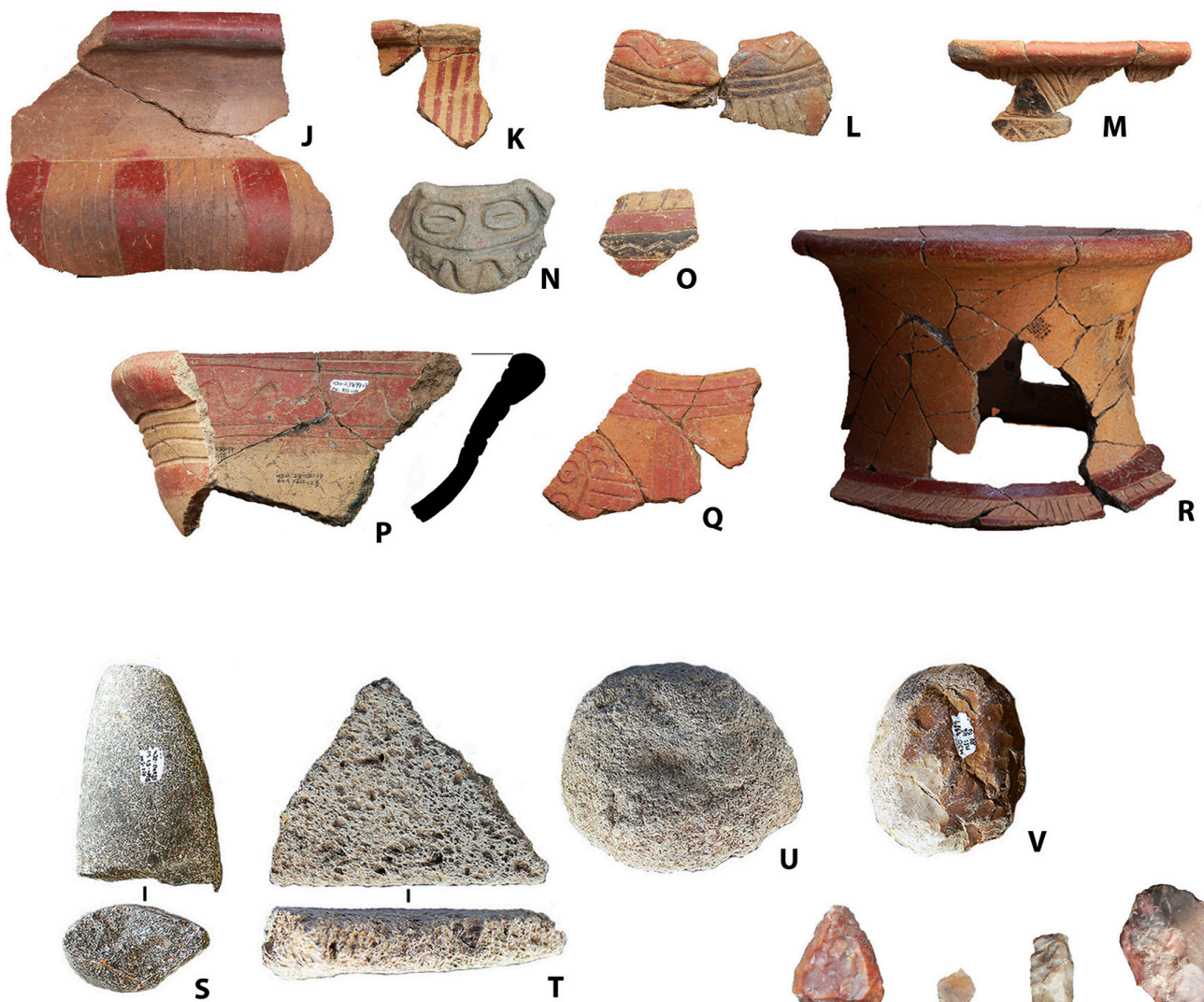

$1 \mathrm{~cm}$
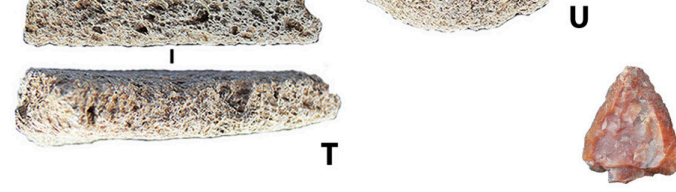

$\mathbf{W}$

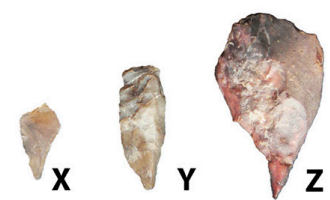

Figura 4: Conjuntos artefactuales de la fase Loma B-I (A-I), Loma B-II (J-R) y Loma B en general (S-Z). Representados aquí están tipos cerámicos como Toya Tricromo Inciso (A,I); Palmar Inciso $(\mathrm{C}, \mathrm{G})$; Diría Inciso $(\mathrm{H})$ y Bocana Inciso (J); nueva nomenclatura se ha establecido para los restantes. S. hachoide; T. metate; U. rompe nuez; V. percutor; W. preforma de punta; X, Y. lascas puntiagudas y Z. buril. Las figuras de cerámica y lítica no lasqueada difieren en escalas. 
tanto en la clasificación como en el ordenamiento de las categorías en el tiempo. Sin embargo, la tendencia ha continuado, sobrevalorando la presencia de Bocana en las cuantificaciones de sitio y contextos típicamente Tempisque. Elementos culturales de ocupaciones precedentes irremediablemente tomarán parte en contextos actuales por los procesos transformacionales relacionados con factores edafológicos y antropogénicos. Además, por ser una vajilla que casi se decoró por completo, Loma B siempre se hará notar afectando la representatividad objetiva en los conteos cerámicos fase por fase; situación esta, particularmente, visible en las cuantificaciones incluso de contextos claramente más tardíos de Manzanillo, donde categorías propias de Loma B llegan a sumar hasta entre el 13 y el $20 \%$ de fragmentos diagnósticos. Por último, la distribución de tipos cerámicos en los contextos de Manzanillo rebela de forma convincente, una sucesión estilística y morfológica, de modo tal que, la tradición bicroma de incisos precocción, en vez de seguir en el tiempo, es paulatinamente sustituida por nuevas categorías que rescatan de ella modos generales de forma y decoración.

El componente Loma B de Manzanillo abre además, nuevas perspectivas para evaluar el contexto sociocultural concerniente a la última parte de Orosí, hasta la fecha, muy pobremente conocido y, como decíamos, usualmente confundido con el del P. Tempisque. El mismo Lange (1980) originalmente no ha estado plenamente convencido de situar Loma B en su propio contexto como en el caso de Hoopes (1987) que lo vincula expresamente a la sociedad "formativa" temprana Tronadora (Orosí). En consecuencia, se ha tendido a anticipar inusitada y desacertadamente el surgimiento de la sociedad aldeana al 800/600 a.C. (Lange, 1980; Odio, 1992), asumiendo que este sea uno de los parámetros socioculturales principales que caracteriza al P. Tempisque.

A la fecha, Manzanillo no es solamente el sitio que mejor documenta el patrón de vida de las poblaciones Loma B del Orosí Tardío, sino que también el que permite ubicarlo en una amplia secuencia de ocupación en términos de hábitats litorales. Hasta no poseer datos de mayor amplitud y diversidad geográfica sobre la ocupación Loma B en la Gran Nicoya, el parámetro actual apunta hacia una sociedad sencilla; unidades familiares que practicaban una economía mixta. El ámbito costero diverso en recursos debió influir para mantener una mayor estabilidad y permanencia en el tiempo, lo que se deduce en el continuo de ocupación Loma B I y Loma B II.

Las actividades agrícolas en Manzanillo eran importantes, pero dentro de un rango de diversidad y no de especialización. Ello se desprende de conjuntos artefactuales con énfasis en labores de molienda, el maíz debió ser parte importante en la dieta, pero morfológicamente, la mayoría de las bases de moler no parecen corresponder a metates sensu stricto, sino de bases para macerar y triturar (tubérculos y frutos arbóreos) aparte de la relevante incidencia de machacadores y rompenueces (Figura 4U). 
En cuanto a las muestras arqueofaunísticas, debe subrayarse la diversidad de taxones representados en las muestras a partir de 1234 elementos óseos de Loma B clasificados a nivel de familia (Cuadro 2). En cuanto a la caza terrestre, sobresale Cervidae (venado), pero también se halló evidencia de otras especies que merodean cerca de las huertas como Dasypodidae (armadillo), Procyonidae (mapaches y coatíes) así como de diversos roedores como conejos, ratas y ratones de monte. Debe destacarse la frecuencia de Iguanidae (Garrobo) y algunas especies de víboras y serpientes (Boidae, Colubrydae y Vyperidae).

La pesca incluye familias que se distribuyen en diversos hábitats costeros, desde sustratos arenosos blandos, arrecifes rocosos y coralinos y eventualmente, de mar adentro. La diversidad de peces óseos y cartilaginosos es mayor con respecto a las siguientes fases y en cuanto a los datos suministrados por Gutiérrez (1998) para Nacascolo, lo que podría vincularse a una menor selectividad de especímenes. Curiosamente, se hallaron huesos de dos ejemplares que habitan en agua dulce, de las familias Erythrinidae (guabina) y Pimeolidae (roncador). En cuanto a invertebrados, sigue siendo una incógnita el aparente no aprovechamiento de esta clase de recursos; aunque es posible que las valvas no hayan sido transportadas hasta los lugares de cochura y consumo, sino desechadas cerca de la costa (Solís y Herrera, 2005), puede argüirse que en zona litorales donde arqueológicamente se han encontrado concheros en los periodos Precerámico y del Cerámico Temprano -como en el caso del Pacífico Central de Panamá- esto ha sido posible en medio de hábitats estuarinos y deltaicos de gran productividad y no de ambientes rocosos y de arrecifes como los predominantes en la bahía Culebra (Richard Cooke, comunicación personal 2104).

Indicadores de actividades diferenciadas se perciben al final de la fase, donde se hallan indicios de una industria lasqueada incipiente dirigida a la reducción de nódulos de cuarzo en lasquillas puntiagudas (Figura 4X, Y). En los sedimentos de esta fase, se halló un trozo de peridotita de tono ligeramente verdoso, sugiriendo desde entonces, la intervención de estas materias primas. Con base en la discusión del próximo apartado sobre el desarrollo de la tradición del jade (piedras verdes en general) a partir de la fase Orso, toma mayor relevancia la fecha del Entierro 5 del sitio La Regla en el Golfo de Nicoya de 800-500 a.C. (Guerrero et al., 1992) que pese a no estar acompañado de cerámica diagnóstica, está asociada a un jade "dios-hacha" y otros abalorios. En materia de rangos cronológicos, ambos datos se prestan para especular en antecedentes inesperadamente tempranos para el surgimiento de dicha tradición.

Loma B propone, por tanto, una reconsideración de las divisiones de la secuencia cultural en la Gran Nicoya, en la cual debiera estipularse una cronología para el Orosí Tardío. Según los fechamientos que se discutirán en el próximo apartado, 300 a.C. parece ser el apropiado como marcador del final del P. Orosí e inicio del P. Tempisque. En el Arenal, Hoopes (1987) había indicado que la fecha de 830 (400 a.C.) 1 d.C. 
Cuadro 2: Distribución por familia de la fauna recuperada en los contextos de la fase Loma B (Orosí Tardío) de Manzanillo. Identificaciones realizadas por Máximo Jiménez.

\begin{tabular}{|c|c|c|c|c|}
\hline & Familia & Nombre común & Cantidad & $\%$ \\
\hline \multirow[t]{2}{*}{ Chondrichthyes } & Carcharhinidae & Tiburones, cazones & 5 & 0,41 \\
\hline & TOTAL & & 5 & 0,41 \\
\hline \multirow[t]{31}{*}{ Peces } & Albulidae & Macabies, zorros & 11 & 0,89 \\
\hline & Ariidae & Cominatas, bagres & 4 & 0,32 \\
\hline & Balistidae & Chanchos, calafates, gatillos, etc. & 5 & 0,41 \\
\hline & Batrachoididae & Sapo, picadores, fraile, brujas & 15 & 1,22 \\
\hline & Belonidae & Aguja, Maraos & 112 & 9,08 \\
\hline & Carangidae & $\begin{array}{c}\text { Jureles, palometas, pámpanos, } \\
\text { etc. }\end{array}$ & 130 & 10,53 \\
\hline & Centropomidae & Róbalos, gualajes & 3 & 0,24 \\
\hline & Clupeidae & $\begin{array}{c}\text { Sardinas, arenques, machuelos, } \\
\text { etc }\end{array}$ & 6 & 0,49 \\
\hline & Diodontidae & Erizo, puerco & 21 & 1,70 \\
\hline & Eleotridae & Gobios, dormilones & 1 & 0,08 \\
\hline & Elopidae & Macabis, Machetes, Torpedo & 3 & 0,24 \\
\hline & Engraulidae & Anchoas, anchovetas, boquerones & 2 & 0,16 \\
\hline & Erythrinidae & Guabina o guavina (agua dulce) & 1 & 0,08 \\
\hline & Fistulariidae & Corneta & 1 & 0,08 \\
\hline & Gerreidae & Mojarras, palmitos & 7 & 0,57 \\
\hline & Haemulidae & Roncadores, burros, viejas, etc. & 343 & 27,80 \\
\hline & Kyphosidae & Chopas & 1 & 0,08 \\
\hline & Labridae & Peine, cuchillo, doncellas, etc. & 9 & 0,73 \\
\hline & Lutjanidae & Pargos & 53 & 4,29 \\
\hline & Mugilidae & Lisas & 1 & 0,08 \\
\hline & Muraenidae & Morenas & 19 & 1,54 \\
\hline & Paralychthdae & Lenguados, hoja & 2 & 0,16 \\
\hline & Pimelodidae & Plateada, barbudos (agua dulce) & 1 & 0,08 \\
\hline & Poecilidae & Sardinas vivíparas & 1 & 0,08 \\
\hline & Polynemidae & Bobos, barbudos & 3 & 0,24 \\
\hline & Pomacentridae & Jaquetas, damiselas, pintañas, etc. & 7 & 0,57 \\
\hline & Pristigasteriidae & Sardinas machete & 3 & 0,24 \\
\hline & Scaridae & Loro, pocochos & 28 & 2,27 \\
\hline & Sciaenidae & Corvinas, lambes, cajeras, etc. & 7 & 0,57 \\
\hline & Scombridae & Melvas, atunes, barriletes, etc. & 3 & 0,24 \\
\hline & Serranidae & Meros & 45 & 3,65 \\
\hline
\end{tabular}

Cuadernos de Antropología 2015, 25(1), 67-97 / ISNN 2215-356X

http://revistas.ucr.ac.cr/index.php/antropologia 
Cuadro 2 (continuación): Distribución por familia de la fauna recuperada en los contextos de la fase Loma B (Orosí Tardío) de Manzanillo. Identificaciones realizadas por Máximo Jiménez.

\begin{tabular}{|c|c|c|c|c|}
\hline & Familia & Nombre común & Cantidad & $\%$ \\
\hline & Sparidae & Sargos, palmas & 7 & 0,57 \\
\hline & Stromateidae & Palometas, pampanitos & 2 & 0,16 \\
\hline & Tetraodontidae & Tamboriles & 1 & 0,08 \\
\hline & TOTAL & & 859 & 69,61 \\
\hline \multirow[t]{3}{*}{ Anfibios } & Bufonidae & Sapo común & 32 & 2,59 \\
\hline & Leptodactylidae & Rana & 3 & 0,24 \\
\hline & TOTAL & & 35 & 2,84 \\
\hline \multirow[t]{7}{*}{ Reptiles } & Boidae & Boa constrictor & 3 & 0,24 \\
\hline & Crocodylidae & Caimán & 1 & 0,08 \\
\hline & Colubridae & Culebra & 3 & 0,24 \\
\hline & Iguanidae & Iguana, garrobo & 26 & 2,11 \\
\hline & Kinosternidae & Tortuga de pantano & 1 & 0,08 \\
\hline & Viperidae & Víboras, serpiente & 4 & 0,32 \\
\hline & TOTAL & & 38 & 3,08 \\
\hline \multirow[t]{2}{*}{ Aves } & Psittacidae & Loros, papagayos & 1 & 0,08 \\
\hline & TOTAL & & 1 & 0,08 \\
\hline \multirow[t]{7}{*}{ Mamíferos } & Cervidae & Venados & 282 & 22,86 \\
\hline & Dasypodidae & Armadillos & 2 & 0,16 \\
\hline & Heteromydae & Ratón de monte & 2 & 0,16 \\
\hline & Leporidae & Conejo & 3 & 0,24 \\
\hline & Muridae & Rata & 6 & 0,49 \\
\hline & Procyonidae & Mapaches y coatíes & 1 & 0,08 \\
\hline & TOTAL & & 296 & 23,99 \\
\hline
\end{tabular}

de la base del sitio Bolívar, donde están mínimamente representados Tongibe Beige y Bocana Inciso, marcaba el término del Tronadora Tardío (Orosí). En el futuro próximo, deberá sustentarse con mayor cantidad de fechamientos absolutos a Loma B, especialmente en lo que respecta a su inicio, pues el de 800 a.C. deja dudas, ya que el salto cualitativo entre Tronadora/Chaparrón/La Pochota y Loma B pudo tomar más tiempo del que se estima.

\section{La transición Orosí-Tempisque en las tierras bajas y litoral pacífico}

En la literatura arqueológica se ha reconocido que el estilo Rosales (Figura 5D,F,G) marca una época en la evolución de las sociedades de la Gran Nicoya; para Lange representa la categoría principal de la fase 
Orso en la bahía Culebra, sustentándola por medio de la fecha 400 (262) 90 a.C. para sitio Vidor (Lange, 1980). En playa Tamarindo, Rosales y Obando de Líneas Negras (Figura 5B) son los más comunes del "Bicromo", aquel último caracterizado por el patrón brochado cf. Usulután. Si bien Obando parece no estar presente en las colecciones de sitios del valle del Tempisque, se dan otros tipos incisos afines a Rosales como Ballena y Tamino (Figura 5A, C). La fecha de 754 (271 a.C.) 60 d.C. para el sitio Ortega, donde Rosales está muy bien representado desde los niveles basales, apoya la idea de la antigüedad del contexto adscrito a este estilo tricromo inciso. Otras fechas tempranas con la presencia de Rosales proceden de los sitio Méndez, 410 (329) 132 a.C. (Norr, 1986) y, El Carmen 390 (144a.C.) d.C.54 (Ryder, 1986a).

A nivel de componentes cerámicos, las colecciones de la fase Orso en Manzanillo son contundentes en mostrar la presencia de cada uno de todos aquellos tipos mencionados; la escisión entre los periodos Orosí y Tempisque está muy bien reflejada en la vajilla cerámica que, en efecto, se vuelve más versátil en formas, técnicas decorativas e iconografía (Figura 5A-G). Los contextos más prístinos en Manzanillo asociados a Orso provienen del Módulo 8, entre los niveles 50 a $100 \mathrm{~cm}$ donde su popularidad alcanzó el $57 \%$. En relación con las características estilísticas y morfológicas de la vajilla Orso, cabe subrayar, no obstante, que persisten formas generales de Loma B, por ejemplo, las ollas monocromas de abertura amplia (de aquí, lo imprecisas que resultan categorías tradicionales como Montecristo y Hermanos Beige) y otras que persisten en el ámbito del mismo Rosales. Entre los diseños, sobresalen la figura del murciélago y otras representaciones que pueden hacer alusión a saurios y felinos. La sencillez y limitada variabilidad morfológica de Rosales de los contextos domésticos de Manzanillo sustenta el supuesto de que las vasijas especiales y de mayor elaboración de este tipo eran de uso preferencial en actividades rituales y funerarias.

Si bien se asume lo significativo de los cambios acaecidos en la sociedad del P. Tempisque sobre las poblaciones aldeanas incipientes, indicadores socioeconómicos no han podido ser debidamente evaluados, en parte, por la escasez de contextos funerarios y domésticos arqueológicamente documentados y la falta de estudios regionales enfocados sobre patrones de asentamiento que incluyan muestreos más intensivos. Para Baudez (1967), los habitantes del valle del Tempisque practicaban la agricultura, pero no formaron aldeas muy grandes. En el valle del Sapoá, cementerios adscritos al P. Tempisque, como Las Pilas, distintivos por los agrupamientos de lavas volcánicas, son de considerable tamaño y ya muestran indicadores de diferenciaciones sociales, de acuerdo con la presencia de jades. Sin embargo, no fue posible obtener inferencias sólidas de patrones de subsistencia, ya sea por la dificultad de ubicar los sitios, o bien, porque asentamientos más grandes pueden estar a considerable distancia de los cementerios (Lange y Scheidenhelm, 1972).

En la zona de Granada, Nicaragua, los asentamientos relacionados al Orosí-Tardío/Tempisque mostraron una tendencia similar, aunque la presencia de una aldea de cierto tamaño sugiere un proceso incipiente de nuclearización (Salgado, 1996). Por otro lado, llama la atención la ausencia de muchos de los componentes de esta fase en la secuencia de Tilarán donde no solamente está ausente Rosales, sino otros elementos del conjunto cerámico que se esperaría para Orso. Esto está apoyado por el tope inferior al $2 \sigma$ de las fechas que en sitio Bolívar se relacionan con la fase Arenal Tardía, a partir de ca. 300 d.C. La posibilidad de un 



Figura 5: Tipos cerámicos del sitio Manzanillo correspondientes a las fases Orso (A-G), Mata de Uva I (H-L) y Mata de Uva II (M-S). Representados aquí están Ballena/Tamino incisos (A,C); Obando Línea Negra (B); Rosales Esgrafiado (D,F,G); Zelaya en sus variantes bicroma (J) y tricroma (M); Las Palmas Rojo sobre Beige (I); Charco Negro sobre Rojo (N); Cervantes Punteado (P); Guinea Inciso (Q), Mojica Impreso (R) y Lavanderos de Reborde Lateral (S). Para los restantes se utilizó una nueva nomenclatura. 
despoblamiento en la cuenca del Arenal para este lapso (la hipótesis alternativa es la de la no presencia de Rosales en tierras altas) no debería descartarse; en zonas de pie de monte más occidentales de la cordillera, se especula que la ausencia de esta fase podría obedecer a la actividad volcánica del Rincón de la Vieja que acumuló una gruesa capa de pómez sobre ocupaciones congruentes a Loma B II (Hernández y Sánchez, 2013).

Los contextos litorales relacionados con la parte más temprana del P. Tempisque tampoco han brindado datos muy concluyentes en términos de patrones de asentamiento. La investigación en Manzanillo ha revelado que durante este momento no se da un cambio sustancial en el uso de la terraza en relación con Loma B y, quizás, se seguía dando la presencia permanente o estacional de pequeños caseríos, la distribución de evidencia cultural a través de la terraza es muy similar para ambas fases, lo cual se deduce de la evidencia de sondeos realizados por Solís y Herrera (2005) y de nuestras excavaciones. Sin embargo, hay indicadores muy claros en cuanto a la intensificación de las actividades relacionadas con la manufactura de objetos especiales y a ciertas actividades de tipo ritual. En el Módulo 13 se identificó un rasgo específico alrededor del cual se procesaban huesos para convertirlos en herramientas y adornos; también se halló evidencia de talle, corte y pulido de peridotitas, una piedra a la que se le atribuían propiedades análogas a las del jade. De igual forma, en el Módulo 10 se descubrió un asidero de piedras relacionado con osamentas de venados de lo que inferimos se trataba de un sacrificio ritual.

Es significativo también el hallazgo en el Sector 7, de un emplazamiento ritual y funerario de características muy similares a las encontradas en otros sectores de la Gran Nicoya y que se distinguen por los conjuntos circulares de ignimbritas de donde se encontró un único entierro y una hornilla ritual (Figura 3A). Los hallazgos de Manzanillo referentes a la fase Orso deben verse de forma complementaria la mano con hallazgos recientemente encontrados en el suroeste de la bahía. Nos referimos al emplazamiento funerario Loma Corral en las cercanías de playa Panamá en la misma bahía Culebra (Figura 1). En tumbas coronadas por agrupamientos circulares de ignimbritas, los ajuares en este sitio asocian tipos como Santiago Aplicado (escaso en Manzanillo), Rosales y Ballena, incisos y vasijas análogas a Usulután, a diversos abalorios de jades y piedras de diverso material como peridotitas, calcedonias, serpentinas, cuarzos y lutitas. Los colgantes manifiestan un simbolismo muy diverso, afín en muchos aspectos, con el expresado en la cerámica, con temas antropomórficos y zoomórficos, centrado en figuras como aves, murciélagos, tortugas, entre otros (Guerrero, 2007). Algunos entierros parecen tipificar los enseres de los joyeros, mostrando marcada similitud con el instrumental recuperado de los contextos de Manzanillo asociados con el término de la fase Loma B y especialmente a Orso.

Los conjuntos artefactuales que acompañan a los difuntos desde la primera parte del P. Tempisque (Figura 6), se distinguen, entonces, por la calidad y lo suntuoso, no solo de los implementos corporales de jades, sino también por exquisitas piezas cerámicas de los tipos Rosales y Usulután y de metates calados con gran fineza (e.g. Ferrero, 1977). El punto aquí es destacar que el jade (el simbolismo adscrito a las 
propiedades físicas de las piedras verdes y a su imaginería) ya era objeto de veneración y todo apunta que para entonces ya estaba fuertemente arraigada en la sociedad y su cosmología. Al respecto, se ha recalcado el profundo simbolismo mágico-religioso del contexto del jade en Costa Rica (Guerrero, 1993; Salgado y Guerrero, 2005; Snarskis, 1993).

La fase Orso, re-evaluada a partir de la zona temprana de la secuencia estratigráfica de Manzanillo, y su convincente vínculo con la evidencia mortuoria de Loma Corral, ofrece una nueva perspectiva del contexto sociocultural en el cual incursionó la tradición del jade en territorios del sur de Nicaragua y norte de Costa Rica. No se puede sustentar la idea de que ingresara al margen de contactos con pueblos históricamente vinculados a desarrollos nucleares de Mesoamérica donde una tradición análoga comenzó desde siglos atrás. En Costa Rica; la presencia de jades olmecas y mayas ha sido ampliamente documentada, pero se desconoce si para las épocas previas a Orso se daba una transferencia activa de objetos norte-sur (Snarskis, 1993). De igual forma, es indudable que desde un punto de vista diacrónico, la tradición del jade en Costa Rica tiene desde sus inicios una identidad propia, parece trazar un desarrollo propio con estilos bien definidos. La mayoría de artículos arqueológicos de jade en nuestro país son de materiales diversos, pero que se pueden conseguir localmente, una mínima cantidad, por contactos a larga distancia (Bishop y Lange, 1993).

Otro punto de discusión se refiere al paralelismo entre la incursión del jade y de estilos cerámicos cuyos acabados, técnicas decorativas y temática están íntimamente ligadas a tradiciones mesoamericanas. Al respecto, debemos mencionar que si bien existen paralelismos, estos obedecen a desarrollos considerados principalmente propios de la periferia sur de Mesoamérica. En el caso de Rosales, se considera que sus centros de producción se situaban en el sur-oriente de Nicaragua. Un análisis de elementos traza de ejemplares Usulután, el que es considerado un horizonte marcador del sur de Mesoamérica entre 300 a.C. y 250 d.C., concluye que tenían versiones manufacturadas en Nicaragua, pero siempre dentro de los confines de la Gran Nicoya (Bishop, 1994; Healy, 1988; Lange et al., 1990; Lange et al., 2003). Por consiguiente, buena parte de los especímenes Usulután identificados en el noroeste de Costa Rica no deben interpretarse necesariamente como artículos obtenidos por intercambios a larga distancia.

Durante la zona temprana del P. Tempisque se dan, por lo tanto, indicadores de diferenciación social que en contextos domésticos se reflejan en industrias incipientes para la manufactura de adornos de jades. A nivel funerario, los ítems mortuorios descuellan por su calidad estética y marcado contenido mágico y ritual. Los cementerios y sepulturas específicas subrayan el prestigio social de los poseedores de ese conocimiento y de las habilidades técnicas o bien, de diferencias a nivel de linajes o clanes. Sin embargo, no se reflejan aún, diferencias sociales marcadas a partir de la complejidad y tamaño de las sepulturas y de la cantidad, calidad y variabilidad de artefactos en los ajuares para determinados ocupantes (Guerrero, 1993; Salgado y Guerrero, 2005). 


\section{La intensificación del culto al jade, fase Mata de Uva I}

La discusión anterior respalda la idea de que el surgimiento de la tradición del jade se ha tomado como uno de los principales referentes de una nueva era en el desarrollo sociocultural de la Gran Nicoya a partir del 300 a.C. Sin embargo, los indicadores arqueológicos de la sociedad aldeana inicial siguen sin conocerse a cabalidad. Los componentes culturales de Manzanillo, relacionados con la parte inicial de P. Tempisque y algunos otros sitios, solo ofrecen pistas someras. En el contexto de bahía Culebra, parece que solo a partir de la siguiente fase, Mata de Uva, se palpan indicios más consistentes de cambios en el patrón de vida.

Lange (1980) había asignado extensa duración a la fase Orso (300 a.C. a 300 d.C.) mientras que a Mata de Uva un desarrollo más breve (300 a 500 d.C.) dando la impresión que solo hasta después del 300 d.C. los cambios son más intensos. Llama la atención que se llegara a considerar al tipo cerámico Zelaya (Figura $5 \mathrm{~J})$ parte de aquel proceso, cuando su estilo decorativo coincide más con el de "decoración lineal" de la vieja nomenclatura, que al predominante en Orso. Otras categorías que cronológicamente se han asociado a Orso, como las distintivas por los ondulados rojo sobre beige/crema -Las Palmas y Matazana (Figura 5I) (Baudez, 1967)- parecen reflejar, además, desarrollos posteriores a nivel estilístico a partir de categorías muy típicas de aquella misma fase.

La estratificación cultural de Manzanillo ubica, en efecto, a Las Palmas y a Zelaya dentro de un componente cerámico posterior a Orso, el cual ocupa la parte más profunda de una secuencia de desechos culturales adscritos a Mata de Uva, la siguiente fase de la bahía. Se sugiere una fecha más temprana para el inicio de Mata de Uva que la originalmente propuesta (Lange, 1980), de modo tal que para distinguirla se acuda a una separación Mata de Uva I y Mata de Uva II. En apoyo con lo anterior, un contexto con una vasija Las Palmas en la base de un montículo en sitio El Carmen de Guayabo de Bagaces, fechó 390 (144 a.C.) 54 d.C. 54. Sobre este punto, fechamientos absolutos obtenidos por Herrera y Solís (2008) de un piso de cerámica al que se dio seguimiento en las excavaciones del 2007-2009 en Manzanillo son bastante concluyentes sobre el rango 100 a 300 d.C., propuesto aquí para la parte más temprana de Mata de Uva (Mata de Uva I), a saber, 90-260 d.C. y 120-340 d.C. (Véanse las figuras 3C y D y 5H-L).

El análisis de contextos del módulo 14 y 15, que incluyen aquel piso de cerámica, indica que solo cerca del $25 \%$ del material es análogo a Rosales y componente adscrito (Orso), en tanto, Mata de Uva I representa cerca del $50 \%$ entre categorías pintadas, aplicadas, incisas y monocromas.

En Manzanillo, Mata de Uva I muestra un incremento sustancial de las actividades humanas y un cambio drástico en el uso del sitio, el cual proseguirá a la siguiente fase. El micro-patrón de asentamiento que albergaba caseríos durante Loma B y Orso con restos extensivos, pero en bajas densidades, da lugar a un incremento considerable en la intensidad de las actividades, sin embargo, estas se concentran en un sector específico en las proximidades del que fue el cauce de un riachuelo. Los conjuntos líticos hacen hincapié en labores artesanales y no tanto en aquellas relacionadas con la subsistencia, por ejemplo, artefactos de 
percusión, abrasión y perforación; herramientas y objetos especiales sin terminar son muy comunes, entre ellos partes de alhajas de hueso y piedras verdosas (Figura 6). Los pisos ocupacionales asociados con estas fases se distinguen por los escombros de hornillas y depósitos de arena como agentes abrasivos y térmicos que facilitaron el rompimiento, talle y desbaste de nódulos.

Las actividades artesanales muestran diversos grados de destreza, desde simples modificaciones de materiales de piedra, hueso y cerámica desechada, hasta procesos que requieren mayores niveles de experticia como la reducción de nódulos silíceos en finos taladros o el talle, corte y perforado de diversas piedras semipreciosas. La producción heterogénea en materiales y procedimientos, y el no verse reflejados indicadores tangibles de producción en cadena o que esta se dirija a ítems específicos y estandarizados, sugiere que estos espacios no constituían propiamente talleres especializados. Se debe indicar, no obstante, que aún no se cuenta con información comparativa de sitios contemporáneos con Manzanillo como para evaluar niveles de especialización artesanal y producción a gran escala.

Se desconoce aún de un asentamiento grande y permanente relacionado con el P. Tempisque en las proximidades de la bahía Culebra, aunque valga indicar que en terrazas superiores del mismo sitio Manzanillo se ha identificado presencia de componentes culturales de este periodo (Solís y Herrera, 2005). Por ahora, la información sugiere, más enfáticamente a partir de Mata de Uva I, pequeños campamentos de artesanos y pescadores que recurrentemente se acercaban a la costa atraídos por los recursos del medio y por las posibilidades de intermediar en el comercio litoral-tierra adentro. Cementerios relativamente cercanos al entorno de la bahía (Loma Corral, Finca Linares) que enfatizan la presencia de ajuares funerarios con ornamentos de "jades" apoyan esta idea (Guerrero, 2007; Herrera, 1998). Además, son diversos los contextos que a nivel de la bahía denotan actividades especializadas en la producción de cerámica, extracción y procesamiento de sal y quizá pesca a gran escala a través de grandes y numerosas trampas entre las playas Manzanillo y Sombrero (Aguilar, 2006; Bonilla y Calvo, 1990; Solís, 1998; Solís y Herrera, 2003).

\section{EI término de la secuencia Tempisque en Manzanillo: cuestionamientos sobre la tran- sición Tempisque-Bagaces}

Los datos suministrados atrás indican que la fecha 300 d.C. permanece como un referente válido para situar un periodo que en la nomenclatura pasada se llamó "Decoración Lineal". En la secuencia del valle del Tempisque se incluyeron tipos como Cervantes, Zelaya en su variante tricroma, Lavanderos, Guinea; Charco; así como los policromos López y Nosara, distintivos por el uso de la línea blanca delineativa (Baudez, 1967). En las fases Mata de Uva, Santa Elena y Tamarindo, este conjunto se distingue además por la variante Tola Tricromo (Lange, 1980). Junto a otros tipos como Congo y Mojica impresos, todo este conjunto encaja consistentemente en el componente observado en Manzanillo para Mata de Uva II, el cual está muy claramente estratificado sobre Mata de Uva I (Figura 5), representando, el $45 \%$ del total de elementos diagnósticos entre los niveles 100 y $155 \mathrm{~cm}$ bajo superficie y tan solo el 1,3\% por debajo de este nivel. 

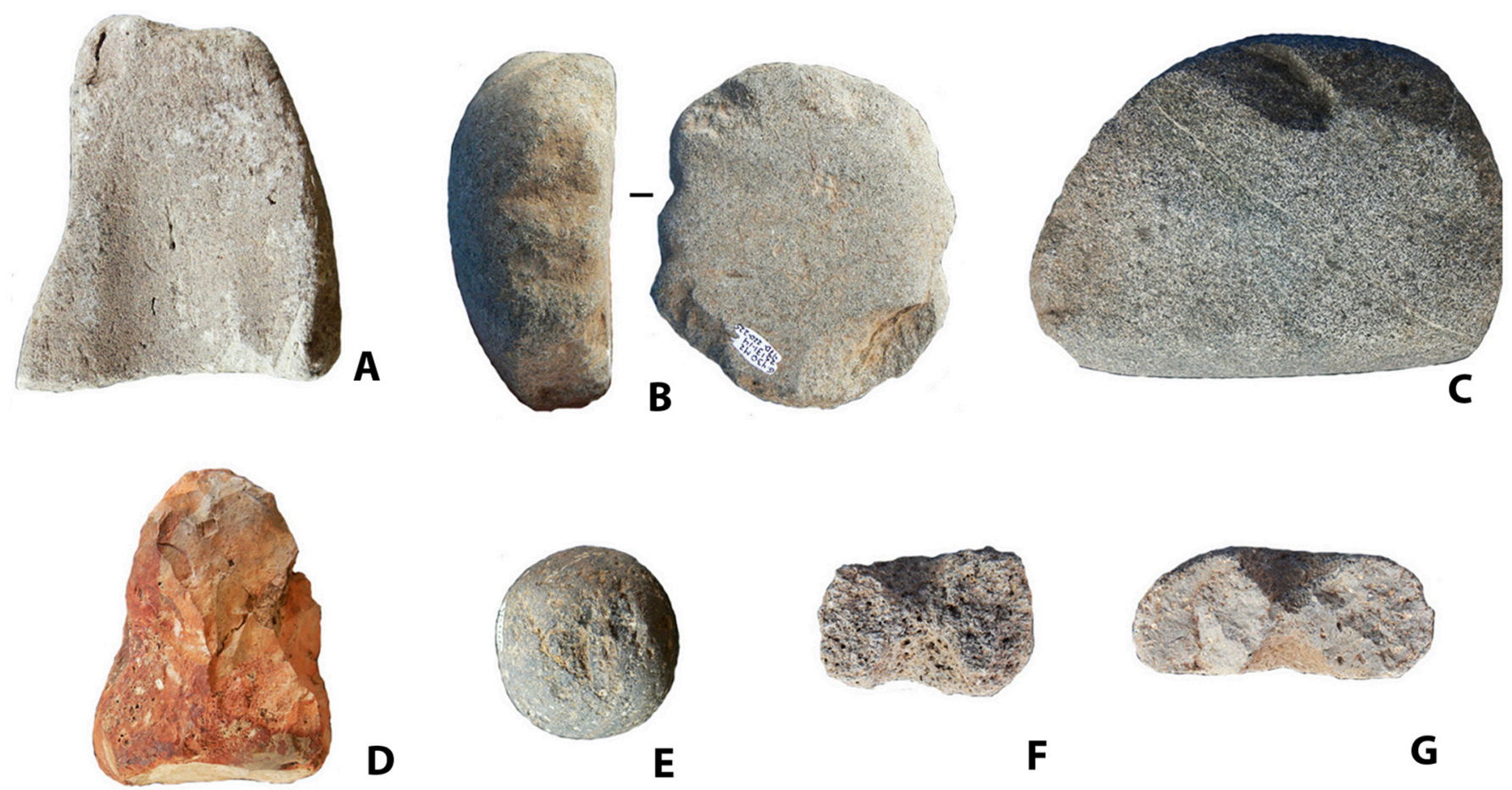

D

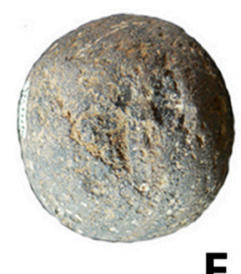

E
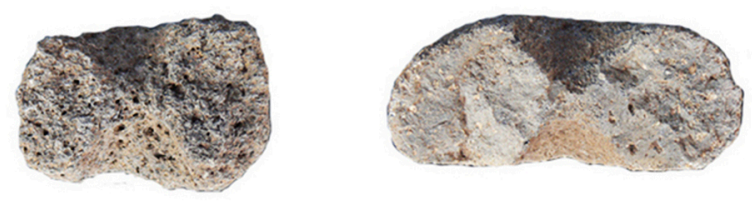

F

G
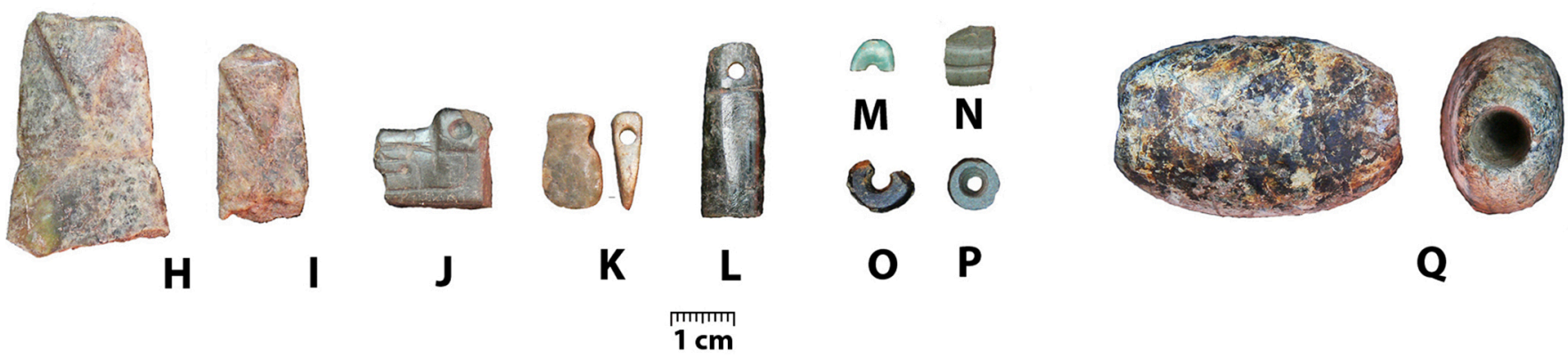

Q

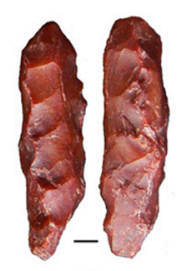

R
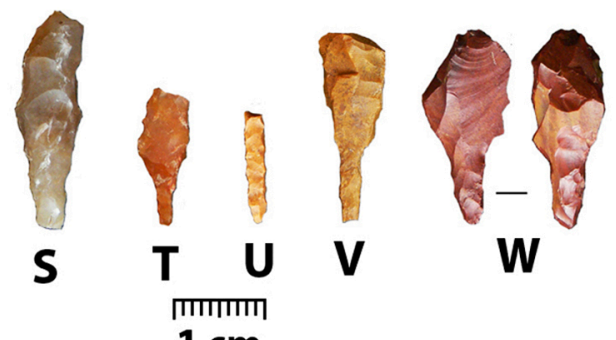

W
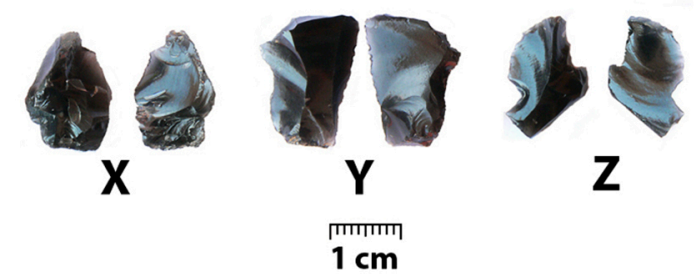

Figura 6: Instrumental lítico y artículos de joyería en proceso de los contextos de las fases Orso y principalmente Mata de Uva I y II de Manzanillo. Abrasivos (A-C); percutores (D, E); preformas de remates de bastón (F,G); pendiente hachoide aviforme (H,I); saurio (J); colgantes en general (K-Q); taladros (R-W) y obsidianas (X-Z). Las figuras de lítica no lasqueada difieren en escalas. 
Una de las principales limitantes había sido la carencia de fechas absolutas para el componente Mata de Uva II, situación que mejoró una vez que Hoopes (1987) lograra la caracterización y fechamientos de los sitios del Arenal, Bolívar -182 (394) 540 d.C. y 432 d.C.(642) 770 y Viboriana, 230 (539) 768 d.C. Otras fechas asociadas al "Policromo Antiguo" (Bagaces Tardío en la nomenclatura actual) sirvieron como referencia para calcular el tope del P. Tempisque en 500/600 d.C.

La evidencia de la cuenca del Arenal y tierras altas de la cordillera permitió, además, documentar un patrón funerario característico por extensos y a veces voluminosos amontonamientos de piedras. Las construcciones de montículos de piedra conforman una tradición después de 300 d.C. (Hoopes, 1987) que al parecer no se desarrolló en las zonas bajas adscritas a la cuenca del Tempisque, península de Nicoya, y costa del Pacífico. Además, se desconocen en la región de Rivas (Healy, 1980), donde los montículos son de tierra y se realizaron como la base de viviendas a lo largo de toda la secuencia.

En Bolívar, por ejemplo, los montículos distinguen por la frecuencia de Mojica Impreso, aparte de ajuares funerarios que incluyen artefactos de molienda poco sofisticados. Algunos elementos culturales en este y otros sitios de la cordillera de Tilarán denotan, eso sí, orígenes extra-regionales como espejos de pirita y tipos cerámicos de la vertiente Atlántica (Guerrero et al., 2005; Hoopes, 1987; Stone y Balser, 1965). Grandes montículos funerarios de piedra de cantos de río se registraron también en hacienda Jericó (Finch, 1986), hacienda Mojica (Ryder, 1986a), Guayabo de Bagaces (Ryder, 1986b) y río Naranjo/valle Bijagua (Norr, 1986). Algunos túmulos son considerablemente grandes y elevados, sin embargo, no se ha podido establecer correspondencia clara con distinciones de rango social: los objetos mortuorios siguen siendo escasos, como en el caso de Sitio Méndez (Norr, 1986). En el sitio Murillo, un montículo contenía hasta 100 tumbas separadas y se construyó en un único episodio (Ryder, 1986b), observación que difiere de sitio Méndez donde el montículo fue paulatinamente formado mientras se dio la ocupación del sitio (Norr, 1986) y que es apoyada por la evidencia de Bolívar donde Hoopes (1987) cree que se dieron varios episodios de actividad funeraria en intervalos por parte de la comunidad o una única familia. La cerámica recuperada de aquellos sitios se asemeja en composición a Bolívar, incluyendo Hermanos Beige, Cervantes y Charco, entre otros.

Muchos montículos pudieron acrecentarse o reutilizarse posteriormente, pues contienen asociaciones con estilos cerámicos que indiscutiblemente tienen fechas posteriores al rango 500/600 d.C., como los policromos Cabuyal, Carrillo y Galo (Ryder, 1986b; Aguilar, 1983). Otro estilo que generalmente se considera dentro de un rango tardío es Chávez Blanco sobre Rojo, cuya abundancia en cementerios parecidos situados en el sector occidental de la cordillera (Hernández y Sánchez, 2013) es coherente con la presunción de que sus centros de producción se ubican en Nicaragua (Abel-Vidor et al., 1990).

La existencia del patrón de túmulos de piedra en la Gran Nicoya también quedó documentada en la zona de Cañas-Liberia, donde se registró un centenar de sitios funerarios con configuraciones variadas. En muchos sitios coexisten categorías cerámicas tanto de las últimas fases del P. Tempisque correspondientes 
a Mata de Uva II como otras que se consideran los estilos marcadores del otrora "Policromo Antiguo". Este hecho, aunado a la dificultad de precisar el contexto sociocultural de dicho periodo, llevó a introducir una nueva nomenclatura en la que se establece el periodo Bagaces como marcador del desarrollo entre 300 y 800/900 d.C. (Guerrero et al., 1994).

Si bien el criterio Bagaces puede ser útil para marcar un fenómeno cultural relacionado con prácticas funerarias, no parece, en opinión del autor, el adecuado para establecer un hito en la evolución sociocultural de la Gan Nicoya. Algunos puntos que debaten esta nomenclatura se refieren a: 1. el patrón funerario descrito no está generalizado a nivel de toda la región, hasta el momento, ni siquiera para el sector sur; 2. si bien hay recurrencia de categorías cerámicas del "Bicromo" y "Policromo Antiguo", debieran sta comprobarse con asociaciones directas a nivel de contextos específicos, por ejemplo ajuares mortuorios, máxime en el entendido de que los túmulos pudieron haberse formarse al cabo de cientos de años; 3. algunas categorías que se manejan son de amplio espectro, especialmente aquellas como Guinea y Hermanos Beige, entre la vajilla no decorada los cambios a corto plazo suelen ser menos perceptibles y; 4. las fechas de 14C, hoy encasilladas dentro del Grupo Bagaces, presentan una distribución desigual además de que no hay forma de contradecir que las fechas más recientes estén asociadas a la policromía. Recalcamos aquí que en Manzanillo, después de Mata de Uva II, se da una brecha tajante con respecto a las fases posteriores con notoria ausencia de componentes de la fase Culebra y, en general, del "Policromo Antiguo".

Sobre este último punto, no existe información contundente de indicadores de que una sociedad políticamente jerarquizada existiera antes del rango marcado por el inicio de la policromía. A este respecto, la secuencia "Bicromo en Zonas"-"Policromo Antiguo" sigue siendo la más acertada para diferenciar este proceso; por lo tanto, el P. Tempisque debería acreditarse hasta al menos el 500 d.C y de seguir empleando el P. Bagaces, hacerlo en términos de la emergencia de las sociedades de rango, esto es, ca. 500-800 d.C.

Sobre el proceso de complejidad social en la cuenca del Arenal, circunscrita a la parte terminal del P. Tempisque, Hoopes (1987) indica que si bien se reflejan esfuerzos comunitarios considerables, la información disponible no permite evaluar más comprensiblemente el estatus socio-político de estas sociedades; el contenido y distribución de ofrendas no ofrecen indicadores contundentes de jerarquías políticas. Valga acotar, sin embargo, que los cementerios pudieron estar diferenciados a nivel regional. Vázquez et al. (1994) indican la posibilidad de ajuares ricos en sitios de la zona Cañas-Liberia, lo cual resultaría razonable si se consideran los espléndidos artefactos que se conocen fuera de contexto arqueológico. Desafortunadamente, el huaquerismo sistemático y a gran escala ha minado en gran medida las posibilidades de interpretación. La evidencia de Finca Linares, en las tierras bajas no asociado a túmulos, es bastante concluyente con respecto a este tipo de indicadores, pero el apogeo de este cementerio excede el tope de los 500 d.C. (Herrera, 1998). Otros elementos diferenciadores de posición social se relacionan con la inversión de energía humana en sepulturas más grandes y complejas que otras dentro de un mismo cementerio. Hay que recalcar aquí, 
además, la ausencia de datos sobre patrones de asentamiento que puedan articularse correctamente con los sitios funerarios en la zonas bajas y altas en la parte costarricense. Para el noroeste de Costa Rica, se sugiere un modelo de sociedad de rangos pero sin centralización política (Vázquez et al., 1994).

La fase Mata de Uva II de Manzanillo es, prácticamente, una prolongación en el tiempo de las actividades anteriormente observadas, sin que se marque una diferencia sustancial en cantidad y calidad. Se mantienen en proporciones similares las muestras de esquirlas, lascas e instrumentos finos de calcedonias y cuarzos, así como de restos malogrados o a medio terminar de colgantes y de piedras verdosas. Parece que el destino final de los objetos terminados no fue estrictamente local: ajuares funerarios contemporáneos y situados en la vecindad de la terraza del sector 2 no exhibieron este tipo de adornos (Hernández, 1998). Los indicadores de Manzanillo para esta fase son elocuentes en afirmar sistemas de producción e intercambio a mayores niveles geográficos, quizá dentro de un sistema sub-regional en el cual el posicionamiento de diversos hábitats costeros formaba uno de los principales eslabones, al tiempo que posibilitaba contactos marítimos. Solo a partir de Mata de Uva, se hallaron 87 pequeños fragmentos de obsidianas, típicos de una industria rudimentaria que antecedió a una más sofisticada que trajeron los Nicaraos (Braswell et al., 1995). Las muestras de Manzanillo podrían provenir de una fuente conocida, relativamente menos lejana, Güinope, en Honduras.

\section{Reconocimientos}

Mi trabajo se realizó bajo contrato, como parte de la gestión arqueológica de Ecodesarrollo Papagayo S.A., quienes además brindaron importante ayuda logística en las diferentes fases del proyecto. La licenciada Claudia Patricia Díaz fue asistente principal a lo largo de todo el proceso de análisis, registro y entrega de las colecciones al Museo Nacional; así mismo, realizó el montaje de todas las figuras y cuadros que se presentan aquí. Agradecemos profundamente la ayuda brindada por Ana Cristina Aguilar en la parte administrativa y a la Dra. Silvia Salgado por sus atinadas observaciones para el proyecto. El Departamento de Antropología e Historia del MNCR permitió amablemente revisar las colecciones de referencia de Loma B del sitio Vidor y del complejo Tronadora.

\section{Referencias bibliográficas}

Abel-Vidor, S. (1980). Dos hornos precolombinos en el sitio Vidor, Bahía Culebra, Guanacaste. Vinculos, 6(2), 43-50.

Abel-Vidor, S., Baudez, C., Bishop, R., Bonilla, L., Calvo, M., Creamer, W., Day, J., Guerrero, J. V., Healy, P., Hoopes, J., Lange, F., Salgado, S., Stroessner, R. y Tillet, A. (1990). Principales tipos cerámicos de la Gran Nicoya. Vínculos, 13(1-2), 35-317. 
Aguilar, A. C. (2006). Informe final de la evaluación arqueológica en el campo de Golf No 2. San José: Empresa consultora C.I.C.P.A.S.S.A. San José: Manuscrito inédito.

Aguilar, C. H. (1983). Introducción a la arqueología de la región del Volcán Arenal: Tetraestratigrafía y secuencia cultural. Anales de la Academia de Geografía e Historia de Costa Rica, (1980-82), 57-87.

Barrantes, R., Smouse, P. E., Mohrenweiser, H., Gershowitz, H., Azofeifa, J., Arias, T. y Neel, J. V. (1990). Microevolution in Lower Central America: Genetic characterization of the Chibcha-speaking groups of Costa Rica and Panama, and a consensus taxonomy based on genetic and linguistic affinity. American Journal of Human Genetics, 46(1), 63-84.

Baudez, C. F. (1967). Rechèrches archéologiques dans la Vallée du Tempisque, Guanacaste, Costa Rica. Paris: Institut des Hautes Etudes de L'Amerique Latine.

Baudez, C. F., Borgnino, N., Laligant, S. y Lauthelin, V. (1992). Papagayo: Un hameau précolombien du Costa Rica. Paris: Editions Recherche sur les Civilisations.

Bishop, R. L. (1994). Análisis de composición de la cerámica en el sur de América Central. Vínculos, 18-19(1-2), 9-29.

Bishop, R. L. y Lange, F. W. (1993). Sources of Maya and Central American jadeite. En: F. W. Lange (ed.), Precolumbian Jade: New Geological and Cultural Interpretations (p.125-130). Salt Lake City: University of Utah Press.

Bonilla, L. M. y Calvo, M. (1990). G-227 Salinas: Un sitio de extracción de sal marina en Guanacaste (Tesis inédita de licenciatura). Universidad de Costa Rica, San José, Costa Rica.

Bransford, J. F. (1881). Archaeological researches in Nicaragua. Smithsonian Contributions to Knowledge, 25. Washington D.C: Smithsonian Institution.

Braswell, G. E., Salgado, S. y Glascock, M. D. (1995). La obsidiana guatemalteca en Centroamerica. En J. P. Laporte y H. Escobedo (eds), VIII Simposio de Investigaciones Arqueológicas en Guatemala, 1994 (pp. 102-112). Guatemala: Museo Nacional de Arqueología y Etnología, Guatemala.

Coe, M. D. y Baudez, C. F. (1961). The Zones Bichrome Period in Northwestern Costa Rica. American Antiquity, 26(4), 505-515.

Constenla, A. (1991). Las lenguas del Área Intermedia: Introducción a su estudio areal. San José: Editorial Universidad de Costa Rica.

Cooke, R. (1995). Monagrillo, Panama's first pottery (3800-1200 cal BC): Sumary and research (19481993), with new interpretations of chronology, subsistence and cultural geography. En J. Barnett y J. Hoopes (eds), Emergence of pottery: Technology and innovation in ancient societies (pp.164-184). Washington D.C: Smithsonian Institution Press.

Cooke, R. y Ranere, A. J. (1992). The origin of wealth and hierarchy in the Central Region of Panama (12000-2000 BP), with observations on its relevance to the history and phylogeny of Chibchan-speaking polities in Panama and elsewhere. En F. W. Lange (ed.), Wealth and hierarchy in the Intermediate Area (pp. 243-316). Washington D.C: Dumbarton Oaks Research Library and Collection.

Corrales, F. (1989). La ocupación agrícola temprana del sitio Curré, Valle del Diquís (Tesis de licenciatura inédita). Universidad de Costa Rica, San José, Costa Rica. 
Corrales, F. (2000). An evaluation of long term cultural change in Southern Central America: The ceramic record of the Diquís archaeological subregion, Southern Costa Rica (Tesis de doctorado inédita). Universidad de Kansas, Kansas.

Ferrero A. L. (1977). Costa Rica Precolombina (2a ed.). San José: Editorial Costa Rica.

Finch, W. O. (1986). A preliminary survey of Hacienda Jerico. Journal of the Steward Anthropological Society, 14(1082-83), 97-103.

Guerrero, J. V. (1993). The context of jade in Costa Rica. En Lange, F.W. (ed.), Precolumbian Jade (pp. 191-202). Salt Lake City: University of Utah Press.

Guerrero, J. V. (2007). Costumbres mortuorias y rituales funerarios de 2000 años Sitio Loma Corral (G- 776 LC3). Playa Panamá Carrillo, Guanacaste (Informe de Arqueología No.-2006). San José: Museo Nacional de Costa Rica. Manuscrito inédito.

Guerrero, J. V., Vázquez, R. y Solano, F. (1992). Entierros secundarios y restos orgánicos de ca. 500 A.C. preservados en un área de inundación marina, Golfo de Nicoya, Costa Rica. Vínculos, 17, 17-51

Guerrero, J. V., Solís, L. F. y Vázquez, R. (1994). El período Bagaces (300-800 d.C.) en la cronología arqueológica del noroeste de Costa Rica. Vínculos, 18(1-2)/19(1-2), 91-110.

Guerrero, J. V, Aguilar, M. y Peytrequín, J. (2005). La cerámica de dos contextos funerarios de las fases Arenal y Silencio, región Arenal-Tilarán. Vínculos, 28(1-2), 87-105.

Gutiérrez, M. (1993). El aprovechamiento de la fauna en el sitio arqueológico Nacascolo, Bahía Culebra, Guanacaste (Tesis de licenciatura inédita). Universidad de Costa Rica, San José, Costa Rica.

Gutiérrez, M. (1998). La ictiofauna del sitio arqueológico Nacascolo, Bahía Culebra, Guanacaste. Vinculos, 22(1-2), 157-187.

Haberland, W. (1992). The culture history of Ometepe island: Preliminary sketch (survey and excavation, 1962, 1963). En F. W. Lange, P. D. Sheets, A. Martíneaz y S. Abel-Vidor (eds), The Archaeology of Pacific Nicaragua (pp.63-117). Albuquerque: University of New Mexico Press.

Hardy, E. T. (1992). The mortuary behavior of Guanacaste - Nicoya: An analysis of precolumbian social structure (Tesis de doctorado inédita). University of California, Los Ángels, California.

Healy, P. (1980). The Archaeology of Rivas Region, Nicaragua. Waterloo, Ontario: Wilfred Laurier University Press.

Healy, P. (1988). Greater Nicoya and Mesoamerica: Analysis of Selected Ceramics. En F. W. Lange (ed.), Costa Rican Art and Archaeology: Essays in Honor of Frederick R. Mayer (pp.291-301). Boulder: Johnson Publishing.

Herrera, A. (1998). Espacio y objetos funerarios en la distinción de rango social en el sitio Finca Linares. Vinculos, 22(1-2), 125-156.

Herrera, A. y Solís, F. (2008). Procesos de trabajo lítico en el sitio Manzanillo durante la fase Orso de la bahía de Culebra. Cuadernos de Antropología, 17-18, 67-88.

Hernández, M. A. (1998). Manzanillo: Sitio costero multicomponente en Bahía Culebra, Guanacaste. Vínculos, 22(1-2), 79-124.

Hernández, A.C. y Sánchez, L. A. (2013). Prospección arqueológica Proyecto Geotérmico Borinquen, Guanacaste. Guanacaste: Instituto Costarricense de Electricidad. Manuscrito inédito. 
Hoopes, J. W. (1987). Early Ceramics and the Origins of Village in Lower Central America (Tesis de doctorado inédita). Universidad de Harvard, Massachusetts, Estados Unidos.

Hoopes, J. W. (1995). Interaction in Hunting and Gathering Societies as a Context for the Emergence of Pottery in the Central American Isthmus. En W. K. Barnett y J. W Hoopes (eds), The Emergence of Pottery (pp.185-198). Washington D.C: Smithsonian Institution.

Lange, F. W. (1980). The Formative Zoned Bichrome Period in Northwestern Costa Rica (800 B.C. to A.D. 500): Based on excavations at the Vidor Site, Bay of Culebra. Vinculos, 6(1-2), 33-42.

Lange, F. W. y Abel-Vidor, S. (1980). Investigaciones arqueológicas en la zona de Bahía Culebra, Costa Rica (1973-1979). Vínculos, 6(1-2), 5-7.

Lange, F. W., Bishop, R. L. y Lange, P. C. (1990). La geología y arqueología de la cerámica prehistórica de la Gran Nicoya. Vínculos, 13(1-2), 7-34.

Lange, F. W. y Scheidenhelm, K. K. (1972). The Salvage Archaeology of a Zoned Bichrome Cemetery. American Antiquity, 37(2), 240-245.

Lange, F. W., Sears, E. L., Bishop, R. L. y Salgado, S. (2003). Local production, non-local production, and distribution: Usulutan and Usulutan-like negative painted ceramics in Nicaragua. En L. van Zelst (ed.), Patterns and Process. A Festscrhrift in Honor of Dr. Edward V. Sayre (pp. 157-169). Washington D.C.: Smithsonian Center for Materials Research and Education.

Lawrence, J. (1989). A Report on the Application of Palynological Data to the Archaeology of Nacascolo, Bahía Culebra, Costa Rica (Tesis de maestría inédita). University of Pennsylvania, Pensylvania, Estados Unidos.

Lothrop, S. (1926). Pottery of Costa Rica and Nicaragua. Contributions from the Museum of the American Indian, Heye Foundation, 8. New York: Museum of the American Indian (Nuevamente publicado como "Cerámica de Costa Rica y Nicaragua" por el Fondo Cultural Banco de América, Managua).

McCafferty G. y Salgado, S. (2000). Reporte preliminar de la evaluación del sitio La Arenera (N-MA65) realizada del 4 al 8 de julio del 2000. Managua: Instituto Nicaragüense de Cultura. Manuscrito inédito.

Norr, L. (1986). Archaeological Site Survey and Burial Mound Excavations in the Rio Naranjo-Bijagua Valley. Journal of the Steward Anthropological Society, 14(1982/83), 135-156.

Norweb, A. H. (1964). Ceramic Stratigraphic in Southwestern Nicaragua. Actas y Memorias XXXV Congreso Internacional de Americanistas (Vol. 1), 551-561. Mexico D.F.

Odio, E. (1992). La Pochota: un complejo cerámico temprano en las tierras bajas de Guanacaste. Vinculos, 17, 1-16.

Ryder, P. (1986a). Hacienda Mojica. Journal of the Steward Anthropological Society, 14(19821983):105-120.

Ryder, P. (1986b). Guayabo de Bagaces. Journal of the Steward Anthropological Society, 14, 121-134.

Salgado, S. (1996). Social Change in a Region of Granada, Pacific Nicaragua (1000 B.C.-1522 A.D.) (Tesis de doctorado inétida). Albany State University, New York, Estados Unidos.

Salgado, S. y Guerrero, J. V. (2005). La distribución de la jadeita en Centroamerica y su significado social. Cuadernos de Antropología, 15, 53-64. 
Sánchez, L. A. (2010). Las ocupaciones tempranas en Bahía Culebra: tecnología, subsistencia y utilización del espacio por comunidades costeras de los periodos Orosí Tardío y Tempisque (500 a.C. a 500 d.C.) en Manzanillo (G-430Mz), Peninsula de Nacascolo, Guanacaste. Guanacaste, Costa Rica, Ecodesarrollo Papagayo S.A. Manuscrito inédito.

Sheets, P. D. (1994). Percepción remota y exploraciones geofísicas aplicadas a la arqueología en áreas volcánicas activas de Costa Rica y El Salvador. Vínculos, 18(1-2)/19(1-2), 31-53.

Snarskis, M. J. (1978). The Archaeology of the Central Atlantic Watershead of Costa Rica (Tesis de doctorado inédita). Columbia University, Columbia, Estados Unidos.

Snarskis, M. J. (1993). The Imagery and Symbolism of Precolumbian Jade in Costa Rica. En F. W. Lange (ed.), Precolumbian Jade (pp. 191-202). Salt Lake City: University of Utah Press.

Solís, L. F. (1998). Nuevos datos de la arqueología de Bahía Culebra, Guanacaste, noroeste de Costa Rica. Vínculos, 22(1-2), 1-44.

Solís, L. F. y Herrera, A. (2005). Procesos de trabajo y áreas de actividad en el sitio Manzanillo (G-430 $\mathrm{Mz}$ ). San José: Museo Nacional de Costa Rica. Manuscrito inédito.

Solís, L. F. y Herrera, A. (2003). Exploración de los estanques de pesca precolombinos \#1 al 5, frente al sitio Manzanillo (G-430 Mz). Museo Nacional de Costa Rica. Manuscrito inédito.

Stone, D. y Balser, C. (1965). Incised Slate Discs from the Atlantic Watershed of Costa Rica. American Antiquity, 30, 310-329.

Vázquez, R. (1986). Excavaciones de muestreo en el Sitio Nacascolo: Un paso adelante dentro del Proyecto Arqueológico Bahía Culebra. Journal of the Stewart and Anthropological Society, 14, 67-92.

Vázquez, R., Lange, F. W., Hoopes, J. W., Fonseca, O., González, R., Arias, A. C., Bishop, R. T., Borgnino, N., Constenla, A., Corrales, F., Espinoza, E., Fletcher, L. A., Guerrero, J. V., Lauthelin, V., Rigat, D., Salgado, S. y Salgado, R. (1994). Hacia futuras investigaciones en Gran Nicoya. Vínculos, 18(1-2), 245278.

Willey, G. R. y Phillips, P. (1958). Method and Theory in American Archaeology. Chicago: University of Chicago Press. 
